\title{
Design of a Thermoelectric Generator for Waste Heat Recovery Application on a
}

\section{Drivable Heavy Duty Vehicle}

\author{
Arash Edvin Risseh and Hans-Peter Nee \\ KTH, Royal Institute of Technology \\ Olof Erlandsson \\ TitanX \\ Klas Brinkfeldt \\ Swerea IVF \\ Arnaud Contet \\ TitanX Engine Cooling Holding AB \\ Fabian Frobenius lng and Gerd Gaiser \\ Eberspacher GmbH \& Co \\ Ali Saramat \\ Scania CV AB \\ Thomas Skare \\ TitanX \\ Simon Nee \\ KTH, Royal Institute of Technology \\ Jan Dellrud \\ Scania CV AB
}

\begin{abstract}
The European Union's 2020 target aims to be producing $20 \%$ of its energy from renewable sources by 2020 , to achieve a $20 \%$ reduction in greenhouse gas emissions and a $20 \%$ improvement in energy efficiency compared to 1990 levels. To reach these goals, the energy consumption has to decrease which results in reduction of the emissions. The transport sector is the second largest energy consumer in the EU, responsible for $25 \%$ of the emissions of greenhouse gases caused by the low efficiency ( $<40 \%)$ of combustion engines. Much work has been done to improve that efficiency but there is still a large amount of fuel energy that converts to heat and escapes to the ambient atmosphere through the exhaust system. Taking advantage of thermoelectricity, the heat can be recovered, improving the fuel economy. A thermoelectric generator (TEG) consists of a number of thermoelectric elements, which advantageously can be built into modules, arranged thermally and electrically, in a way such that the highest possible thermal power can be converted into electrical power. In a unique waste heat recovery (WHR) project, five international companies and research institutes cooperated and equipped a fully drivable Scania prototype truck with two TEGs. The entire system, from the heat transfer in the exchangers to the electrical power system, was simulated, built and evaluated. The primary experimental results showed that approximately $1 \mathrm{~kW}$ electrical power could be generated from the heat energy. In this paper the entire system from design to experimental results is presented.
\end{abstract}

Keywords: Thermoelectric generator, thermoelectricity, waste heat recovery, heavy duty vehicle, heat exchanger, power converter, internal combustion engine, power conditioning, vehicle exhaust, fuel economy 


\section{INTRODUCTION}

In a report published in 2014, the Emissions Database for Global Atmospheric Research (EDGAR) mentions that the European Union (EU) is responsible for $10.5 \%$ of the total $\mathrm{CO}_{2}$ emissions in the world [1]. Due to greenhouse issues and climate changes in the world, governments and different organizations have proposed new policies and rules to decrease the consumption of fossil fuels and thereby the emission of greenhouse gases. One example is the EU's 20-20-20 target which has the goal to produce $20 \%$ renewable energy, to achieve a $20 \%$ reduction in greenhouse gas emissions, and to improve energy efficiency by $20 \%$ compared to 1990 levels [2]. Another example is the European Automobile Manufacturers Association (ACEA) that, with oil and fuel guidelines, is promoting to have environment friendly and sustainable transports [3]. To reach these goals and fulfill the rules and policies active steps must be taken.

After the energy sector, the transport sector is the second largest source of greenhouse gas emissions. This is the only sector in Europe where the emissions are still increasing with $25 \%$ of the total emission. Road transport is a sub-sector of the transport sector and it is responsible for $20 \%$ of the total $\mathrm{CO}_{2}$ emissions in the whole $\mathrm{EU}$ [4]. The main reason of the large amount of $\mathrm{CO}_{2}$ emissions from the transport sector is the use of inefficient internal combustion engines (ICE) in vehicles. As seen in Table 1, approximately one third up to a half of the fuel energy is converted into waste heat and escapes to the ambient through the exhaust system. If the waste heat is converted into useful energy, the overall efficiency of the vehicle will increase and the emission of greenhouse gases and the fuel economy improve. Much work has been done to improve the efficiency of combustion engines internally by improving the mechanical and electrical components of the vehicles. As examples, the six-stroke engines, turbocharging, turbo-compounding, exhaust gas recirculation (EGR), and waste heat recovery (WHR), can be mentioned [5], [6], [7], [8], [9]. However, in average the efficiency of internal combustion engines may still be as low as $15 \%$ [10]. Due to the large amount of waste heat energy the opportunity of WHR drives the scientific communities and companies around the world to improve the fuel economy by recovering heat. Today, the focus of research has been on two types of WHR systems; the organic rankine cycle (ORC) and the thermoelectric generator (TEG). In an ORC, a fluid extracts the heat from the exhaust gases and through a steam turbine, connected to the power shaft, partly unloads the ICE, improving the overall efficiency. F. Liming et al. report a maximum heat recovery of $20 \%$ efficiency form an ORC [11] and $\mathrm{M}$. Wei et al. report $16 \%$ ORCefficiency in a Heavy Duty Vehicle (HDV) [12]. The amount of recovered power is a function of engine load, pressure, temperature, and the type of working fluid. Simulation results on a 2006MY Cummins ISM 10.8 L diesel engine showed an output power between 1 and $9 \mathrm{~kW}$ from an ORC [13]. However, the ORC is a complex system which requires large volume and operates with a hightemperature and pressure steam, and includes moving parts. Furthermore, due to the relatively large time constant in an ORC, the demand of power in the system may be low when the amount of recovered power is high. This issue causes a mismatch in the demand and generation of power which is challenging to handle. Another concern for the ORC is the number of components, which creates a relatively large mass. Therefore, the ORC is a less attractive option for automotive applications but may be more suitable for marine or stationary power generators where the demand of power is comparably constant over time, and space and weight are not as critical as in a vehicle.

Table 1. Fuel energy distribution in combustion engines in percent [14]. Page 2 of 18

\begin{tabular}{|c|c|c|c|c|}
\hline Engine Type & Shaft Power & Cooling & Exhaust & Other \\
\hline Petrol & $25-28 \%$ & $17-26 \%$ & $34-45 \%$ & $5-15 \%$ \\
\hline Diesel & $34-38 \%$ & $16-35 \%$ & $22-35 \%$ & $3-8 \%$ \\
\hline
\end{tabular}

By taking advantage of thermoelectricity, heat can be directly converted to electricity or vice versa where cooling or heating is needed. Thermoelectric conversion is based on the Seebeck effect, which causes electrical energy to be generated when a temperature gradient is applied to thermoelectric elements. Currently, the total output power of existing TEGs is lower than those of ORCs. However, a TEG has other advantages that should be considered. Unlike the ORC, a TEG has no need for maintenance or complicated control systems. It is a compact and non-moving energy conversion system with a stable and fast response. Thermoelectric generators have been used in military applications such as fighting vehicles, nuclear-powered TEGs, and in medical applications, e.g. in pacemakers. Due to their reliability and simplicity, TEGs have even been used in space to provide the satellite electronic components with power [15], [16]. For instance, TEGs have been utilized for power generation in NASAs deep space explorations for over 40 years [17]. The mentioned advantages make the TEG a good candidate for WHR in vehicles, improving the overall efficiency and fuel consumption.

In an analysis made by M. Srinivasan et al. TEGs have the potential to generate 2-3.5 $\mathrm{kW}$ in light and heavy duty vehicles [18]. In two different studies, J.C. Bass et al. reported about a $1 \mathrm{~kW}$ prototype TEG which was designed for an exhaust system in a Cummins NTC 350 diesel engine, using modules (HZ-13 and HZ-14) from Hi-Z technology INC. [19], [20]. It was found that the total output power from the TEG is heavily dependent on the total engine load and less on the engine speed, which is an important design factor. In another study S. Kumar et al. used software tools to simulate a complete TEG containing 50 modules [21]. The main focus in the study was to investigate the impact of various geometries of heat exchangers on the output power, in automotive WHR-systems. Furthermore, the effect of a hybrid configuration with different modules in the same TEG, based on the temperature drop, was investigated. It was found that a transverse heat exchanger in combination with a hybrid configuration gives the highest power which was approximately $800 \mathrm{~W}$. In another successful study at Science University of Tokyo, a TEG was designed for an exhaust system in a Toyota ESTIMA with a 2000 cc gasoline engine. The obtained electrical power at $60 \mathrm{~km} / \mathrm{h}$ was $141 \mathrm{~W}$ and after some system modifications, it increased to 266 $\mathrm{W}$ [22].

In a wide study Q.E. Hussain et al. [23] present the most important design parameters to consider in a TEG in hybrid vehicle applications. It was found that the time constant and the weight of the TEG as well as the backpressure have a significant impact on the generated TEG power and fuel economy. The suggested TEG system was designed for a $2.5 \mathrm{~L}$ gas-electric hybrid vehicle and was able to recover 300-400 W under an EPA-based highway driving cycle. According to another study made by Arsie et al. [24] the recovered TEG power in a personal car equipped with a $70 \mathrm{~kW}$ diesel engine could reach a peak power of $449 \mathrm{~W}$ and the mean power was estimated to $91 \mathrm{~W}$ which corresponds to a $1.5 \mathrm{~g} / \mathrm{km}$ reduction of $\mathrm{CO}_{2}$ emissions. The amount of fuel saving caused by the TEGs is due to the reduction in the mechanical load of the shaft and explained more in detail in [25].

Designing TEGs for automotive applications is a challenging task for several reasons. The most important issue is the large temperature variation of the exhaust gases which is highly dependent on the engine load. Handling of this temperature variation and optimizing 
the system is critical in order to increase the extraction of heat power from the exhaust gases. The main component influencing the power extraction is the heat exchanger (HX). With a suitable HX the highest amount of heat energy can be generated while the maximum temperature on the thermoelectric modules (TEM) does not exceed the thermal limits.

In this paper, the complete design of a TEG system for HDVs is addressed. To the best knowledge of the authors, this is the first time the losses due to the backpressure, the impact of the charge air cooler (CAC) temperature, and the efficiency of the power converter are considered when evaluating the total system efficiency. Never before, a complete TEG including all auxiliaries and actuators has been designed, integrated and evaluated on a real and drivable HDV. During this project, two TEGs and the related components for WHR on a real class 8 truck (440 kW) from Scania were designed, built, installed, and tested. The TEGs were placed downstream of the after treatment system (ATS) and upstream EGR, and were communicating with the main electronic control unit (ECU) of the truck. In order to evaluate such a system, it is important to consider the average TEG-power and the losses when figures of merits such as Watt per weight and price per Watt are estimated. The main targets in this study was to high-light the potential of TEGs in commercial vehicles as well as present, not only the recovered gross power but also the TEG's net- and average power affecting the actual fuel reduction. In the first part, a summary of the physics of thermoelectricity and some important parameters of the thermoelectric material are given. Later, an overview of the design procedure of the TEGs and the related parameters are given. In the last section the experimental results from the complete system in a real environment created in a dyno-cell, are presented.

\section{THERMOELECTRICITY}

When two different conductive materials are connected and exposed to a temperature gradient, charge carriers within the conductors will move in the same direction as the thermal energy. The movement of charge carriers, due to the temperature gradient, creates an electromotive force (emf), which is a function of the temperature gradient and the material properties. This phenomenon is known as the Seebeck effect [26], see Figure 1.

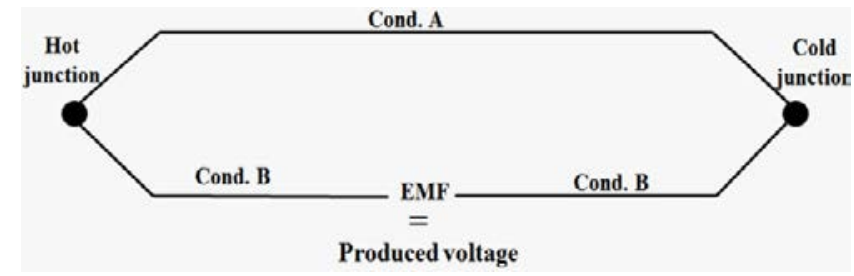

Figure 1. The Seebeck effect on two dissimilar conductors with applied temperature gradient at the junctions creates an emf.

The produced voltage in a thermoelectric circuit is given by

$V=\int_{T_{1}}^{T_{2}}\left(\alpha_{A}-\alpha_{B}\right) d T$

which can be written as

$V=\left(\alpha_{A}-\alpha_{B}\right)\left(T_{1}-T_{2}\right)=\alpha_{A B} \Delta T$,

where the $V$ is the produced open voltage, $T$ is the temperature at the junctions, $\alpha_{A}$ and $\alpha_{B}$ are the absolute Seebeck coefficient of each conductor, and $\alpha_{A B}$ is the Relative Seebeck Coefficient [26]. The most of metals have a Seebeck coefficient of $10 \mu \mathrm{V} / \mathrm{K}$ which makes a TEM inefficient and uneconomical. In the middle of the $20^{\text {th }}$ century during the period of the semiconductors invention, thermoelements based on semiconductors with Seebeck coefficients of higher than that of $100 \mu \mathrm{V} / \mathrm{K}$ were developed. Today's TEMs usually consists of pairs of heavily doped n- and p-type legs that are connected electrically in series to generate a reasonable voltage and thermally in parallel, see Figure 2. The temperature difference causes accumulation of electrons and holes on one side of the conducting legs resulting in a built-in electric field [27].

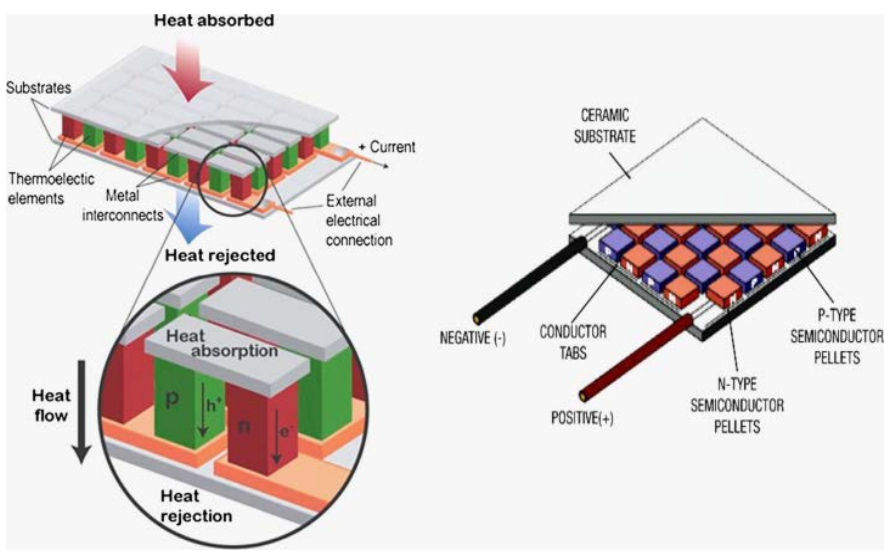

Figure 2. A typical TEM is made by a large number of n- and p-type semiconductors legs sandwiched between two ceramic plates. The figure is used with permission from the authors [28].

Additional thermoelectric effects that can be mentioned are the Peltier and the Thomson effects. The Peltier effect refers to the phenomenon where an electric current applied to two dissimilar conductors actively pump the heat from one junction to another. The Thomson effect refers to reversible heating or cooling in a homogeneous single conductor when it is exposed to a temperature gradient and electrical current simultaneously. This effect causes temperature changes on the conductor.

The energy balance in a thermoelectric pair in power generation mode according to Figure 3, can be described by

$Q_{I N}=\alpha T_{H} I-\frac{1}{2} R I^{2}+\kappa\left(T_{H}-T_{C}\right)$,
$Q_{O U T}=\alpha T_{C} I+\frac{1}{2} R I^{2}+\kappa\left(T_{H}-T_{C}\right)$,
$P_{E}=Q_{I N}-Q_{O U T}=\alpha I\left(T_{H}-T_{C}\right)-R I^{2}$,

Where $Q_{I N}$ and $Q_{\text {OUT }}$ are the input and output thermal power, $R$ is the electrical resistivity, $I$ indicates the current in the circuit, $P_{E}$ is the electrical power, and $\kappa$ is the thermal conductivity of the material [29].

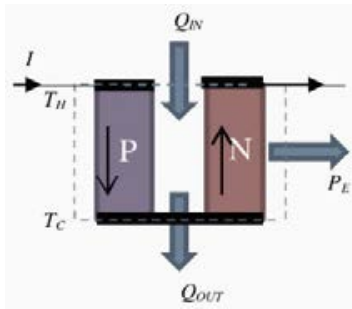

Figure 3. Energy balance in thermoelectric elements shows the input and output heat power as well as the electrical current and power. 
From eq. (4) and (5) it is clear that an optimal TE material exhibits a high Seebeck coefficient $\alpha$, high electrical conductivity $\sigma(=1 / R)$ and low thermal conductivity $\kappa$, which is characterized by the figure-ofmerit $Z T$ [26],

$Z T=\frac{\alpha^{2} \sigma}{\kappa} \cdot T$

where $T$ is the mean operating temperature of the module. In addition, $Z T$ is related to the maximum working efficiency, by

$\eta=\left(\frac{T_{h}-T_{c}}{T_{h}}\right) \cdot \frac{\sqrt{1+Z T}-1}{\sqrt{1+Z T}+\frac{T_{c}}{T_{h}}}$,

where $T_{h}$ and $T_{c}$, are the hot side and cold side temperatures of the module. Nonetheless, the challenge of optimizing $Z T$ arises from the dependence of $\alpha, \sigma$ and $\kappa$ on one another through physical properties of materials, such as Fermi level, effective mass, carrier concentration, lattice thermal conductivity $\left(\kappa_{l}\right)$, and thermal conductivity caused by electrical current $\left(\kappa_{e}\right)$. As illustrated in Figure 4, maximizing $Z T$ involves a compromise between large $\alpha$ and $\sigma$ (shown as $\alpha^{2} \sigma$ ) with low $\kappa$. This behavior is observed at concentrations between $10^{19}$ and $10^{20}$ carriers per $\mathrm{cm}^{3}$, which corresponds to metals and heavily doped semiconductors.

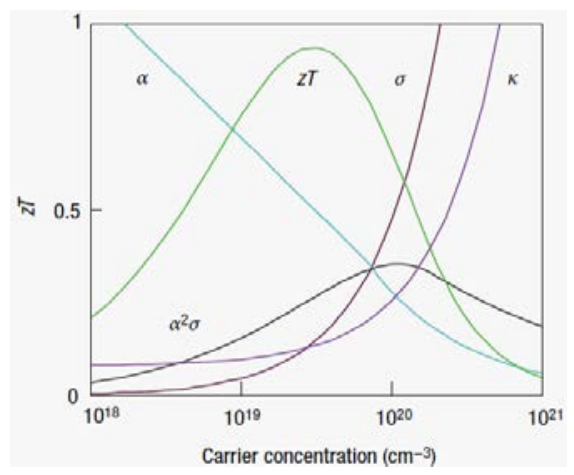

Figure 4. Optimizing $Z T$ through carrier concentration tuning. As seen, thermal and electrical conductivities increase with carrier concentration while Seebeck coefficient decreases. The figure is used with permission from the authors [28].

\section{Bi-Te Alloys}

A thermoelectric material exhibits maximum $Z T$ at a certain temperature, which can be optimized to peak at different temperatures by adjusting the carrier concentration through doping [28]. This means that different TE materials are suitable for various operating temperature ranges. $\mathrm{Bi}_{2} \mathrm{Te}_{3}$ alloys with $\mathrm{Sb}$, Se $\left(\mathrm{Bi}_{2-\mathrm{x}} \mathrm{Sb}_{\mathrm{x}}\right.$ $\mathrm{Te}_{3-\mathrm{y}} \mathrm{Se}_{\mathrm{y}}$ ) have been the primary TE material since the 1950s and are today the most efficient material for low-temperature applications $\left(<200{ }^{\circ} \mathrm{C}\right)$ [30], [31]. For moderate temperature $\left(400-700{ }^{\circ} \mathrm{C}\right)$, halfHeuslers skutterudites, and lead chalcogenides are mainly utilized [32], [33], [34]. For high-temperature operation $\left(>700^{\circ} \mathrm{C}\right)$ silicongermanium alloys are the most suitable alloy [35], [36].

$\mathrm{Bi}_{2} \mathrm{Te}_{3}$ alloys are obtained through a slight change of its stoichiometric composition, n-type or p-type $\mathrm{Bi}_{2} \mathrm{Te}_{3}$. This can be achieved by applying various methods such as doping composition optimization [37], [38], [39], or device engineering [40]. The modules investigated in this study were made of "hot-pressed" Bi-Te based semiconductors, Figure 5.

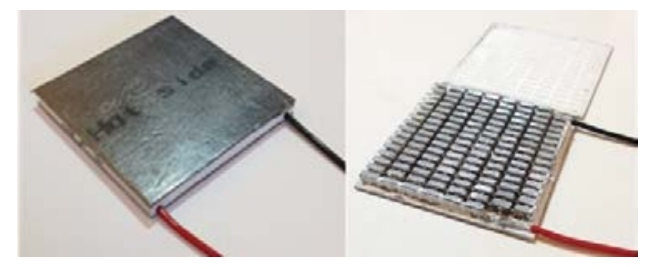

Figure 5. Thermoelectric module, produced by Thermonamic Electronics used in the prototype Scania truck.

\section{Design of the Thermoelectric Generators}

Generally, a TEG system makes use of two HXs for the hot and cold sides respectively, and the TEMs are electrically and thermally connected such that the highest possible power is generated. Furthermore, an electrical power management and control system of hot- and cold media have to be employed to ensure the correct operation of the TEG. This is a multi-disciplinary research project where mechanical, electrical, and thermodynamic sub-systems have to, individually and collectively, work in an optimal way. For that reason the design of a TEG for vehicles is a complicated process, because all components in the system are interdependent, and the final result relies on interaction between different parts. For example, various modules are optimized for different temperatures while the hot and cold side temperature on the other hand are dependent on the design of the HXs which in turn gives rise to a design-dependent amount of losses and, therefore affects the recovered net power. Due to the large variation in exhaust gas temperatures, the greatest challenge becomes designing a system optimized for a wide range of temperatures and power. The only realistic way to overcome these design problems is optimizing the system iteratively. The main parts were studied first and added together into a model of a complete TEG system to be simulated later on. The results of the simulations were used to change and improve the properties and boundary conditions. With the new parameters a more optimized TEG model was built and simulated again. Figure 6 shows the workflow diagram of the design process which was repeated a few times to satisfy the basic requirements. Furthermore, a TEG for WHR in a drivable vehicle has to fulfill other important criteria and standards which are dictated by the automotive industry. For instance, it is important that the TEG is designed in a way that its disturbance on the main and existing systems on-board is minimal. Extremely small, long channels or aggressive surface enhancement in HXs results in very high pressure drop in the exhaust system. Placing the TEG upstream ATS causes high temperature drop and obstructs the ATS function and needs to be avoided. Limited volume, the allowed weight, the reliability, and the cost of the TEG are the other restrictions when it comes to the design and manufacturing process. Furthermore, the design of the TEG should be performed such that the highest possible power can be extracted and stored. The type of TEMs, the design of the HXs, the attachment of the TEMs, the thermal end electrical arrangement of the TEMs, and the power converter and the related control system have a significant impact on the final power extraction of the system. 


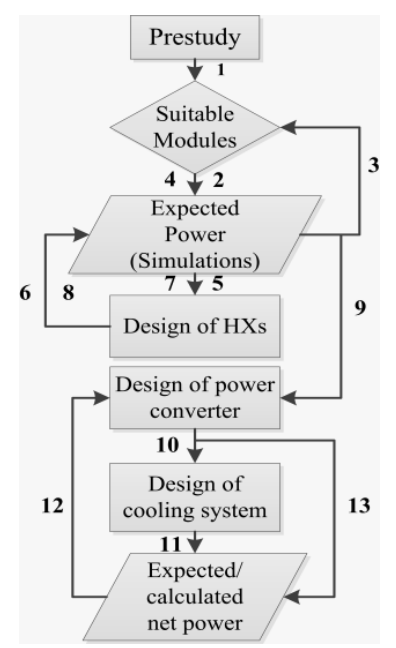

Figure 6. The iterative workflow-diagram to design and optimize the TEG system.

\section{Heat sources and Placement}

There are four heat sources that may be used for TEGs in a diesel vehicle; Exhaust gas, Exhaust gas recycling, Charge air, and Engine coolant. However, there are several aspects to consider when choosing heat source and positioning of the TEG. By placing the TEG close to the hot media streams, unnecessary tubing can be avoided and thereby the pressure and heat losses to the ambient can be minimized. On the other hand, to capture a large part of the heat power from the exhaust system a relatively large TEG should be designed and consequently it cannot be placed anywhere in the vehicle due to space constraints. Also, a larger TEG is heavier and the weight issues have to be considered.

For the key function of transforming a temperature difference between two fluid streams into electrical power it is beneficial if the streams have high mass flows, with high temperature for the hot side and low temperature for the cold side. Fluids with high specific heat capacity are desirable since the temperature will not change rapidly when the heat is transferred. This means that cold sinks will still keep cold and hot sources still keep hot, despite the heat transfer. Furthermore, the fluids should have a high thermal conductivity, which enables that heat is easily pulled, or released, to and from the media. There are four significant fluid streams that are possible to use as heat sources in a modern heavy vehicle:

1. Exhaust gas: This source has the highest mass flow on the vehicle, but the temperature varies significantly with engine load. There are a number of possible locations. However, due to other prioritized emission control systems such as particulate filters and catalysts, the only suitable location is downstream the ATS. Here, temperature can still be quite high (200-400 ${ }^{\circ} \mathrm{C}$ ), and the engine-out temperatures swings are damped due to the high mass of the ATS system which is an advantageous property. The pressure level is closer to ambient and the temperature levels and flows make this source the first choice. A disadvantage is that any additional backpressure in the form of a TEG on the exhaust side means that the engine has to pump the gas through it, which increases the engine load and causes losses.

2. Exhaust gas recycling (EGR): Exhaust gas recirculation is used to limit NOx and particulate emissions. Typically, the exhaust gas is extracted upstream of the turbine at significantly elevated pressures (1-3 bars abs at operation, 5-6 bars abs during exhaust braking). The temperatures are higher than in the ATS $\left(300-600{ }^{\circ} \mathrm{C}\right)$ but the mass Page 5 of 18 flow is low and varies with both engine speed and load. The mass flow is controlled by the engine ECU with an EGR-valve. The ratio of EGR gas to combustion air gas is in the $0-30 \%$ range, i.e. the mass flow is less than $30 \%$ of the air flow in to the combustion. However, the temperatures are close to the highest achievable outside of the cylinders. One important aspect is that the mass flow of the EGR is very dependent on the overall emission control strategy of the engine. Engines can be EGR intensive, have low EGR-rate or even exclude the EGR. The temperature level makes this source the second choice. Placing a TEG in the EGR stream can bring additional benefit; the EGR gases have to be cooled down to $85-95{ }^{\circ} \mathrm{C}$, i.e. additional cooling may be required. With an EGR-TEG, the original EGR cooler can be reduced in size since the TEG does some of this work and hence part of the allowed pressure loss can be transferred to the TEG. To drive the EGR mass flow the engine operates with a negative pressure drop, i.e. the inlet pressure is lower than the exhaust manifold pressure. This means that the engine operates as a pump, and the higher the pressure loss over the EGR line, the higher the pumping loss becomes in order to achieve the same EGR mass flow. Therefore, a requirement is that the pressure drop over the TEG has to be as low as possible.

3. Charge air - air downstream the compressor stage: charge air temperatures are limited ( $\max 200-300{ }^{\circ} \mathrm{C}$ ) and highly engine-load dependent. The temperature variation has a very fast response to engine load since there is very little thermal inertia in the compressor, and the tubing downstream the compressor is usually limited. The mass flow is quite high compared to others on the vehicle and follows engine speed and load. The pressure varies between 1-3 bars abs. The operation medium is air which is poor in terms of heat transfer and requires a lot of surface enhancement to support the heat transfer. Compared to the exhaust the potential is lower simply due to the lower temperatures. Placing a TEG in the charge air has similar benefits as in the EGR stream because the charge air still needs to be cooled down to close to ambient. The pressure drop over the TEG in charge air should also be as low as possible. The engine requires a certain amount of air flow and hence inlet pressure. Any pressure drop results either in lower inlet pressure of the engine, which leads to lower performance, and/or that the engine must run at a higher exhaust backpressure, i.e. the pump work increases.

4. Engine coolant: The operating temperature of the engine coolant is in the range of $95-100{ }^{\circ} \mathrm{C}$, and the pressures are $1-2$ bars abs. The media are typically water-glycol mixtures with very good heat transfer characteristics. However, the temperature level is too low to be interesting for this type of waste heat recovery, at least at the time of writing.

This study focuses on the first two options i.e. using the heat from the exhaust (ATS) and EGR streams. Due to the reasons mentioned earlier in this section, the TEGs have to be placed downstream of the ATS and upstream of the EGR. For the cold streams, the only possible source is the ambient air that the truck moves through, or that the engine cooling fan or an additional one is pulling into the cooling module. Due to the nature of air, large surface areas are required to transfer the heat. Also combining heat exchanger surfaces for gaseous media, for both the heat source and cold sink, would create a very large design due to the large heat transfer surfaces on both sides. Instead, an indirect cooling system of the TEG is appropriated with a heat transfer medium (coolant) on the cold side and the gaseous heat source on the hot side. This way, the cold side heat transfer area can be reduced. In addition, the indirect system makes it possible to have a significant distance between the heat source and heat sink. The coolant can be pumped at low cost and 
typical engine coolants are good energy carriers due to their high density and specific heat capacity.

The data needed to design the TEGs was provided by Scania and contains the engine speed, the gas mass flow, and temperatures in EGR and ATS. All calculations and experimental results were based on the data with 9-steady-state-points that together, create the Long Haulage Cycle (LHC) which emulates real driving conditions for a long haulage, see Table 2 .

Table 2. The 9-steady-state-points (LHC) showing the load of the ICE and conditions in exhaust system. The data is provided by Scania.

\begin{tabular}{|c|c|c|c|c|c|c|}
\hline LHC & $\begin{array}{c}\text { Engine } \\
\text { Speed } \\
(\text { RPM) }\end{array}$ & $\begin{array}{c}\text { Relative } \\
\text { load (\%) }\end{array}$ & $\begin{array}{c}\text { Exhaust mass } \\
\text { flow }[\mathbf{k g} / \mathrm{h}]\end{array}$ & $\begin{array}{c}\text { Exhaust } \\
\text { temp }\left[{ }^{\circ} \mathrm{C}\right]\end{array}$ & $\begin{array}{c}\text { EGR mass } \\
\text { flow }[\mathbf{k g} / \mathrm{h}]\end{array}$ & $\begin{array}{c}\text { EGR } \\
\text { temp } \\
{\left[{ }^{\circ} \mathrm{C}\right]}\end{array}$ \\
\hline 1 & 1000 & 25 & 420 & 248 & 127 & 318 \\
\hline 2 & 1000 & 50 & 556 & 347 & 143 & 452 \\
\hline 3 & 1000 & 100 & 1017 & 386 & 167 & 551 \\
\hline 4 & 1150 & 25 & 423 & 259 & 197 & 335 \\
\hline 5 & 1150 & 75 & 949 & 352 & 194 & 489 \\
\hline 6 & 1300 & 25 & 532 & 251 & 215 & 325 \\
\hline 7 & 1300 & 50 & 803 & 313 & 247 & 425 \\
\hline 8 & 1300 & 75 & 1079 & 346 & 276 & 481 \\
\hline 9 & 1300 & 100 & 1393 & 396 & 213 & 560 \\
\hline
\end{tabular}

\section{Modules}

The thermoelectric module is the main component in a TEG. There are a number of suppliers that manufacture TEMs with different properties. As mentioned before, the performance of a TEM is determined by the figure of merit, $Z T$, and also is dependent on the applied temperatures. Hence, based on TEM supplier's data, parametric sweeps were made early to find an overall design guide and to identify the most suitable TEM. Off-the-shelf TEMs were a project requirement, and therefore only modules where TEMs and supplier data was accessible were considered. Studying the manufacturer's data, there is one key trade-off between heat transfer and electrical power. Combining these properties, it is possible to find a conversion efficiency which is the produced power over heat transfer in to the TEM. Three modules were considered and simulations based on rough data from manufacturers were performed. The modules were used the same thermoelectric material but had different area and height. The results showed that two of the three simulated modules had an efficiency of $3 \%$ at $300{ }^{\circ} \mathrm{C}$ while the efficiency of the third module reached only $2.5 \%$ at the same temperatures. It should be noticed that the first simulations were established with constant hot and cold side temperatures which implies an infinite heat source and an infinite heat sink. However, this is not the case in a real TEG where the gas is cooled down and the coolant is heated along the flow. This issue results in a temperature reduction along the flow, especially on the gas side, and hence the conversion efficiency of the module drops. This shifts the advantage to modules with proportionally less heat transfer, despite having lower conversion efficiency. In order to identify the most suitable TEM, all possible TEMs have to be evaluated in a conceptual TEG design with realistic operating conditions and constraints according to Figure 7.

When a clear picture of the basic operation of a TEM was obtained, a more detailed study on a test bench was performed. A number of possible TEMs were chosen and exposed to temperature gradients based on available heat power and resembling to the 9-point LHC as given in Table 2 . The basic performances and the size of the selected modules are collected in Table 3 . The TEMs were individually placed into the test bench with a controllable heater and cooler. On the Page 6 of 18 electrical side of the TEMs, a load adjusts the voltage from open to short circuit. After reaching stationary temperature conditions, the test bench collects the data and automatically approaches the next temperature conditions until a full temperature map in Figure 7 was completed. Three thermocouples were placed inside the copper block to measure the temperature along the height of the test object. The temperature $T$ was later used to calculate the heat flux $Q$ through each module according to Fourier's law of heat conduction, i.e.

$Q=-\kappa A \frac{\Delta T}{\Delta x}$,

where $A$ is the cross-sectional area of each module and $x$ is the distance between temperature sensor and the source of heat.

Table 3. Specification on the available TEMs provided by manufacturers.

\begin{tabular}{|c|c|c|c|c|}
\hline Manufacturer & Model & $\begin{array}{c}\text { Dim. LxBxH } \\
{[\mathrm{mm}]}\end{array}$ & $\begin{array}{c}\text { Cold- vs. } \\
\text { hot side } \\
\text { temp. }\left[{ }^{\circ} \mathrm{C}\right]\end{array}$ & $\begin{array}{c}\text { Power } \\
{[\mathrm{W}]}\end{array}$ \\
\hline Euroca & TEG2-50-50-40/200 & $50 \times 50 \times 3.4$ & $0-200$ & 40 \\
\hline Euroca & TEG1-40-40-19/200 & $40 \times 40 \times 3.4$ & $0-200$ & 19 \\
\hline Hi-Z & HI-Z-9 & $62.7 \times 62.7 \times 6.5$ & $30-230$ & 9 \\
\hline Hi-Z Tec. & HI-Z-14 & $62.7 \times 62.7 \times 5.1$ & $30-230$ & 13 \\
\hline Quick Ohm & QC161-1.6-15.0M & $40 \times 40 \times 3.2$ & NA. & NA. \\
\hline Thermalforce & TEG126-330-39 & $40 \times 40 \times 4$ & $30-300$ & 7.55 \\
\hline Thermonamic & TEP1-264-1.5 & $40 \times 40 \times 3.6$ & $30-300$ & 7.3 \\
\hline Thermonamic & TEP1-264-3.4 & $40 \times 40 \times 4.6$ & $30-300$ & 5.4 \\
\hline
\end{tabular}

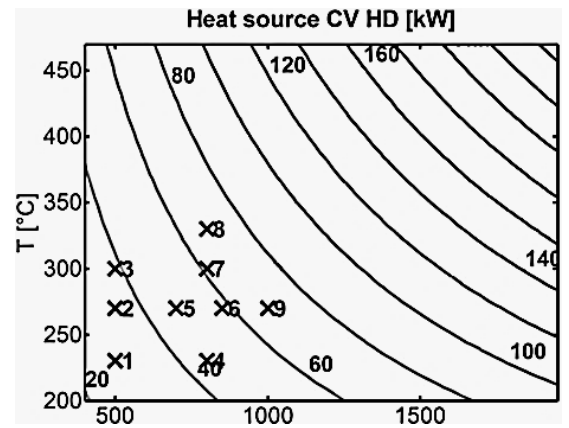

Figure 7. The available heat power $[\mathrm{kW}]$ in different operating points (LHC) in an HDV as a function of temperature and mass flow.

The test bench and the measurement configuration can be seen in Figure 8 . To predict the behavior of the TEMs the stationary data was collected and mathematical models with coefficients as the Seebeck coefficient, the heat conduction coefficient, and the internal resistance of the TEMs were extracted. The models consider four physical laws; Joule heating, the Seebeck and Peltier effects, and the heat conduction.
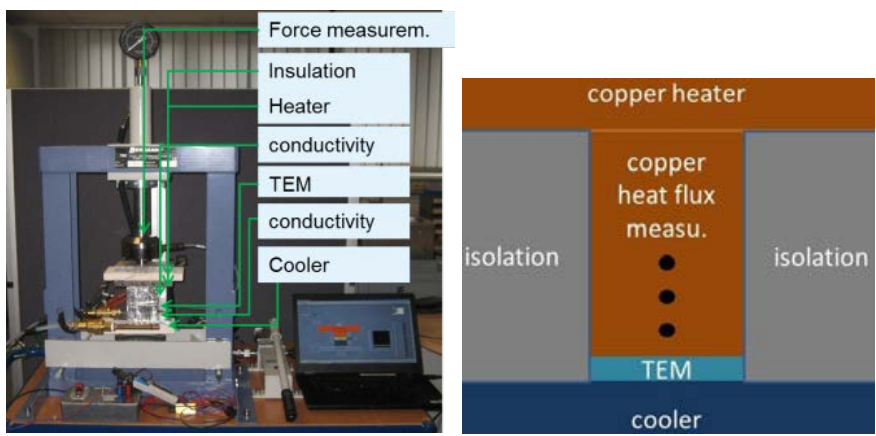

Figure 8. Test bench where the performance of different TEMs were studied (left) and the test object to determine the heat flux through different TEMs (right). The measurement was done by Eberspächer. 
The obtained models were later used in simulations and in the design process of the heat exchangers. Modules from Thermonamic were found to be the most suitable for the application due to performance and cost reasons. The difference between the two Thermonamic modules is the thermoelectric material leg-length which is larger for 3.4 than 1.5. That results in a lower heat flux and thereby the demand of cooling will decrease using 3.4-modules. The results from the measurements are presented in Figure 9.

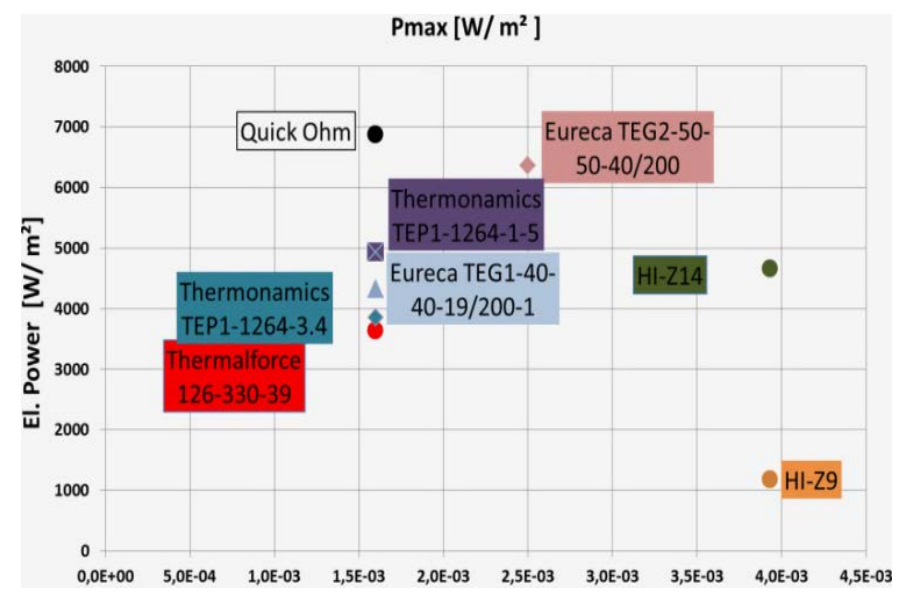

Figure 9. Results from the test-bench measurements. It shows the maximum electrical power per module area vs. cross section area of different modules.

\section{Module Attachment}

The attachment of the modules into the body of the TEG has to meet two important criteria; sufficient and constant pressure onto the modules has to be applied, and it has also to be homogenous over the surface. This improves the heat-power extraction of the HXs and increases the reliability of the system in applications with high levels of vibration.

Two methods to apply force on the modules can be used; internal or external pre-stressing. Employing external spring makes it easier to assemble the modules and applies relatively homogenous pressure over the system resulting in a less complicated HX design. Simulations based on FEM with different force configurations were performed. However, the result of the simulation showed extremely uneven pressure over the cold channel, see Figure 10. In the middle part of the channel between two brackets, there was no pressure while below the brackets the pressure reaches its highest level. According to the specifications, Thermonamic 3.4 has to be mounted with an even pressure of 14 bars which cannot be obtained with the configuration in Figure 10.
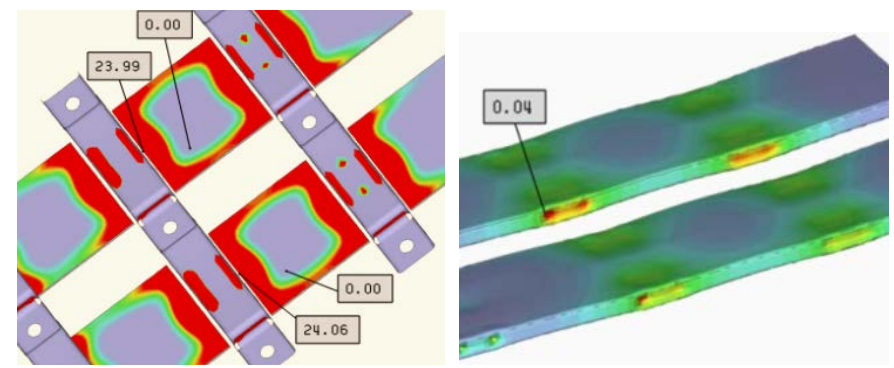

Figure 10. Simulation results of the surface pressure in [bar] on the coolant channel for the ATS-TEG (left) and deformation rate of the coolant channel (right). The pressure on the surface is not even and could break down the TEMs and deform the channel.

Page 7 of 18
In addition, due to the thermal expansion during the operation, the pressure unevenness will increase even more and risk cracking the modules. In order to improve the pressure distribution another model was developed with reinforcement of the cold channel by adding fins inside and increasing the ribs on the clamps. The new configuration resulted in a more homogenous pressure distribution but still does not satisfy the criteria for correct installation. It was shown that the only way to have homogenous pressure over the channels was to employ an expansive clamp over the channel, see Figure 18.

\section{EGR-TEG}

The thermoelectric modules have a significant thermal conductivity from the hot side to the cold side. If no heat is transferred from the cold side of the module, the temperature will quickly be the same on both sides because of the thermal conductivity, and the output power drops to zero. Furthermore, when a heat source has a limited heat capacity the heat transfer would reduce the temperature of the heat source which is valid for the heat sink as well. On both sides, this would reduce the temperature difference over the modules and thereby the electrical power would decrease. By having continuous streams of fluids an infinite source and sink is emulated. To increase the heat capacity HXs are employed. The HX surfaces can be designed in different ways, but the overall function is that they enhance heat transfer in two principal ways. By exposing the medium to a larger surface than the projected area the heat transfer will increase. Typically this is accomplished through surface roughness, or more common, fins on the surface. Furthermore, HXs increase mixing in the medium. By continuously split and mix the flow along the fin surface, the already cold media is replaced, or mixed with hot media, i.e. it reduces the thickness of the boundary layer. This process can be achieved in any of the flow regimes (laminar, intermediate or turbulent) but a turbulent flow is desired. To increase the heat transfer using enhanced heat transfer surfaces results in a pressure drop of the medium over the HX. Increasing the contact surface increases the integrated viscous shear forces in the boundary and thereby the flow friction resulting in pressure drop. Since the efficiency of the TEG is low, it is important to limit the pressure drop to an absolute minimum to reduce the losses in the system. This means that the hydraulic losses, i.e. the losses due to the pressure drop in the system, should not adversely influence the produced electrical power by the TEGs. This is another optimization problem to find an acceptable loss i.e. a maximum net power output. In other words, the entire TEG needs to be balanced in terms of electrical power extracted vs. other powers wasted. For heat transfer surfaces, this means that it is not allowed to use too "aggressive" fins with e.g. a large number of louvers and small fin pitches. It should be noticed that the environment in the EGR and the ATS are completely different and therefore two principally different types of fins were chosen. For the EGR-TEG smooth rectangular fins and for the ATSTEG which is able to manage higher pressure drop, offset strip fins with large fin pitches and fin lengths were chosen.

To study the steady-state performance at various loads of the TEGs and to virtually test different modules and HX surface designs, a number of discretized lumped-element models were developed. The modules were experimentally mapped at Eberspächer company facilities and were modeled to be able to predict the heat transfer, idle voltage, and the internal resistance of the TEMs. A considerable number of simulations on the conceptual level were performed to find the overall size and aspect ratios of the TEGs. The simulations showed that a wide (cross gas flow), short (along gas flow) was the most optimum HX design. The reason is that the heat transfer along the flow gives a temperature profile that drops gradually along the 
flow in the TEG, i.e. modules downstream perform less, and that the pressure drop becomes lower with a wider but shorter design which is desirable in terms of hydraulic losses. In a more detailed study the installation considerations and the optimum fin configurations (tradeoff between pressure drop and performance) could be handled. The study showed that more modules would have brought more performance but at a relatively higher cost.

Parametric sweeps were performed on the conceptual level to give the initial design hints on how to design HX surfaces as well as selection of TEM. When selecting the best TEM technology, a key performance index of most net electrical power per TEG core volume was used due to the space constraint on the truck. Basically, the task was to generate the most net power out from a certain space available on-board. To find the net power of the TEG, the actual fuel consumption penalty had to be estimated in an early phase of development and therefore the pure hydraulic loss of the TEGs had to be calculated. These hydraulic losses were evaluated under assumed constant pumping efficiencies (pumping power over the consumed power) of $46 \%$ on the gas side and $5 \%$ (fluid electrical pump) on the fluid side. Possible increased fan work was not considered at this stage.

The sweeps on the HX parameters were made individually for three modules from Thermonamic and Thermalforce which showed fairly good performance per area and cost according to earlier test-bench measurements (Figure 9). The performance of a complete EGR-TEG was simulated for the 9-point LHC which was performed on an ideally packed TEG-core with one layer of TEMs in cross-counter flow operation. On the hot side; fin pitch, -thickness and -height were swept, and on the cold side; channel diameters and -pitch were swept, see Figure 11.

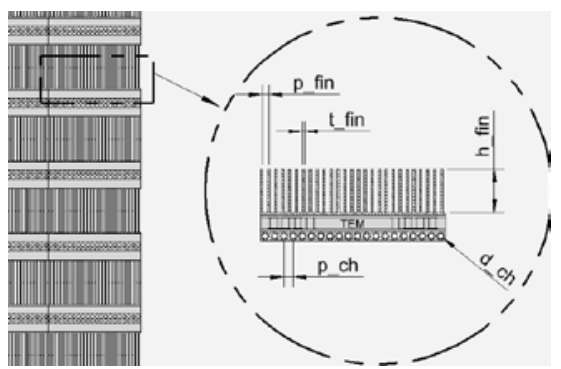

Figure 11. Ideally packed TEG core model for parametric studies. Parameters swept: Fin pitch (p_fin), fin height (h_fin), fin thickness (t_fin), channel pitch (p_ch) and channel diameter (d_ch).

With some parameters e.g. fin height, the net power could basically increase to infinity, hence a value of 5-10 \% from the maximum values were selected for space considerations. Among the most important parameters, fin pitch and -height have a significant effect on the heat exchanger performance. If too small, the pressure drop and hence hydraulic loss will increase significantly. The effect of these parameters is less sensitive on the coolant side due to the high heat capacity of the fluid. The number of modules affects the flow area and hence the pressure drop, and also the amount of the heat capacity each module is loaded with. The results from parametric sweeps are presented in Table 4. According to this simulation the Thermonamic TEP1-263-3.4 generates the highest power over the core volume. The reason is that the module has larger heat flux per unit area $\left(10.7 \mathrm{~W} / \mathrm{cm}^{2}\right)$ which in turn, generates higher electrical power than the other modules. However, it should be noticed that the high heat flux requires a large cooling system to keep the temperature difference. In other words, there is trade-off between the generated electrical power and the power consumed by the cooling system. Page 8 of 18
Generally, when the heat source and the heat sink have a limited capacity which is the case in automotive applications, a module with lower heat flux is desirable. Further simulations on a complete TEGsystem showed that the thicker version of Thermonamic modules (264-3.4) generates the same amount of net power as for instance 1264-1.5 because the thinner one has larger heat flux and requires a more extensive cooling system. Due to the lower heat flux and the same amount of output power as the similar modules, Thermonamics TEP1-164-3.4 was selected to be used in the TEGs.

Table 4. Results from parametric sweeps over 9-point LHC. Optimum values are shown on the heat exchanger surface parameters. Effective power is the difference between electrical power and hydraulic pumping work.

\begin{tabular}{|c|c|c|c|c|c|c|c|c|c|c|c|c|}
\hline TEM & & $\begin{array}{l}\text { The } \\
\text { TEP }\end{array}$ & $\begin{array}{l}\text { Irmona } \\
1-1264\end{array}$ & $\begin{array}{l}\text { mic } \\
1.5\end{array}$ & Thermo & $\begin{array}{l}\text { tonamic } \\
1263-3 .\end{array}$ & ${ }_{4}^{\text {TEP1 }}$ & Therm & Ial Fore & - TEC & 3-069-3 & $340-39$ \\
\hline TEM thickness & $\mathrm{mm}$ & & 3.6 & & & 3.6 & & & & 11 & & \\
\hline TEM proj. area & $\mathrm{mm} 2$ & & 1600 & & & 900 & & & & 4503 & & \\
\hline Number of TEM's & & 100 & 200 & 300 & 100 & 200 & 300 & 50 & 75 & 100 & 200 & 300 \\
\hline Fin height & $\mathrm{mm}$ & 25 & 20 & 16 & 25 & 20 & 16 & 25 & 20 & 16 & 12 & 12 \\
\hline Fin pitch & $\mathrm{mm}$ & 1.8 & 1.8 & 1.4 & 1.8 & 1.8 & 1.4 & 1.4 & 1.4 & 1.2 & 1.1 & 1.1 \\
\hline Fin thickness & $\mathrm{mm}$ & 0.5 & 0.5 & 0.5 & 0.5 & 0.5 & 0.5 & 0.5 & 0.5 & 0.5 & 0.5 & 0.5 \\
\hline Channel diameter & $\mathrm{mm}$ & 0.8 & 0.5 & 0.5 & 0.8 & 0.5 & 0.4 & 0.8 & 0.6 & 0.6 & 0.6 & 0.4 \\
\hline Channel pitch & $\mathrm{mm}$ & 1.6 & 1.0 & 1.0 & 1.6 & 1.0 & 0.8 & 1.6 & 1.2 & 1.2 & 1.2 & 0.8 \\
\hline Flow ratio (coolantigas) & $\mathrm{kg} / \mathrm{kg}$ & 2 & 2 & 2 & 2 & 2 & 2 & 2 & 2 & 2 & 2 & 2 \\
\hline TEG specific eff. power LHC avg. & W/dm3 & 34.1 & 45.5 & 48.2 & 50.9 & 79.8 & 89.9 & 53.3 & 60.7 & 65.3 & 56.5 & 44.1 \\
\hline TEM Efficiency (el./.h.t.) & & $2.7 \%$ & $2.7 \%$ & $2.5 \%$ & $3.3 \%$ & $3.4 \%$ & $3.3 \%$ & $5.7 \%$ & $5.4 \%$ & $5.4 \%$ & $4.7 \%$ & $4.3 \%$ \\
\hline
\end{tabular}

The final core design also includes space for springs (EGR-TEG) or clamps (ATS-TEG) for providing contact pressure over the heat exchanger, but also space for TEM cables and clamp screws. After tuning the detailed design, changing the TEG location and size, final predictions of performance were established for the EGR-TEG. The design now also included bypass control in order to be able to limit the TEM temperature to the maximum allowed. Figure 12 and 13 shows the final EGR-TEG, the CAD and its placement. After the final assembly and bench tests it was revealed that the models overpredicted both heat transfer and performance. Better agreement was achieved with the models if more care were taken to describe the "dead" volumes inside the core, i.e. the sections for cables and unused space inside the core, between the TEMs.

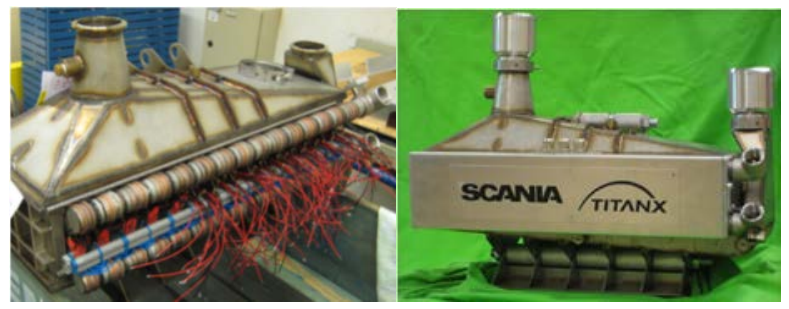

Figure 12. EGR-TEG with electrical connections of the TEMs (left) and the finalized TEG (right).

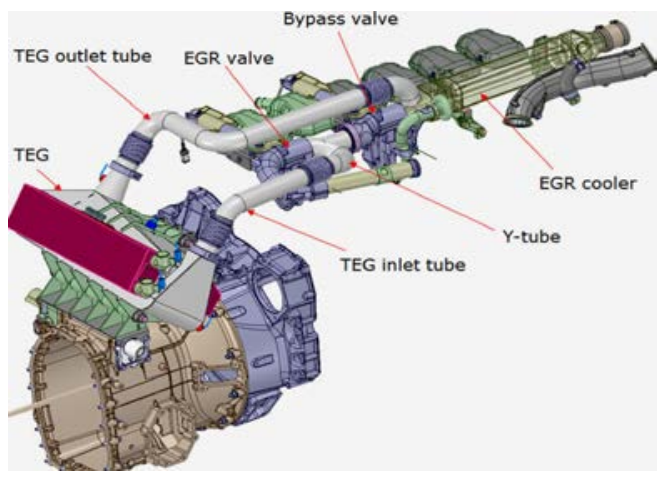

Figure 13. The CAD schematic over the EGR-TEG placement and parts of the ICE. 


\section{ATS-TEG}

During the study, it was found that the only possible place for the exhaust-TEG was downstream ATS because the influence of the TEG on the existing exhaust system would be minor. To keep the heat energy from the exhaust system, the TEG has to be placed directly after the ATS as shown in Figure 14 where there is a free volume of $250 \mathrm{~mm} \times 500 \mathrm{~mm} \times 300 \mathrm{~mm}$. Since all the exhaust gases pass through the ATS, the backpressure issue should also be considered and minimized. The challenge here is also to find the TEG configuration with highest possible energy density within a predefined volume. Similar simulations as for the EGR-TEG were performed to create a conceptual design. To reduce the complexity of the calculations, five different configurations for two different Thermonamic modules, with two fin heights and two TEG heights according to Table 5, were simulated. Based on the temperature and mass flow in the ATS, simulations were running and at this moment it was confirmed that the selected TEM has the best performance also per unit price.

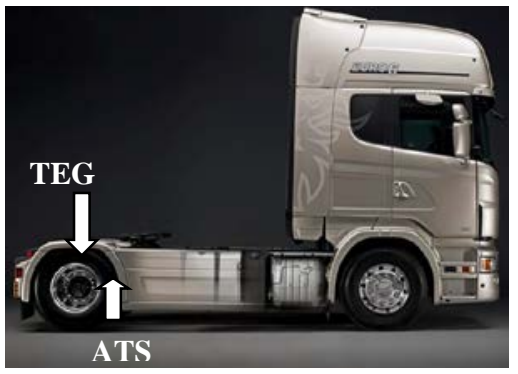

Figure 14. The only possible place for ATS-TEG in the truck is downstream of the ATS.

The results were used as initial assumptions, in a more detailed complete-system simulations, which were performed based on the cross-counter flow as shown in Figure 15. The iterative solver based on the Newton-Raphson algorithm was employed to investigate the behavior of the gross- and net power of a complete ATS-TEG with different configurations.

Table 5. The table shows the combination of different TEG-configuration and Thermonamic modules in the ATS-TEG which were used in the simulations.

\begin{tabular}{|c|c|c|c|c|}
\hline TEM & $\begin{array}{c}\text { TEG } \\
\text { height } \\
{[\mathrm{mm}]}\end{array}$ & $\begin{array}{c}\text { Fin } \\
\text { height } \\
{[\mathrm{mm}]}\end{array}$ & $\begin{array}{c}\text { Nr. of } \\
\text { sub- } \\
\text { TEG }\end{array}$ & $\begin{array}{c}\text { Nr. of modules } \\
\text { in the TEG }\end{array}$ \\
\hline TEP1-264-1.5 & 440 & 6 & 16 & 256 \\
\hline TEP1-264-1.5 & 430 & 9 & 13 & 224 \\
\hline TEP1-264-3.4 & 440 & 6 & 15 & 240 \\
\hline TEP1-264-3.4 & 440 & 9 & 14 & 224 \\
\hline TEP1-264-3.4 & 430 & 9 & 12 & 208 \\
\hline
\end{tabular}

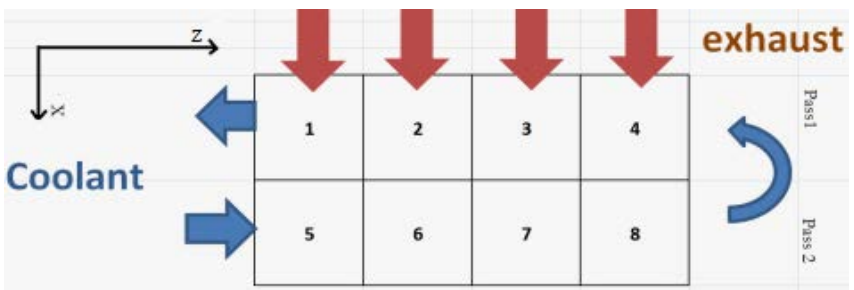

Figure 15. 2D-schematic of ATS- and EGR-TEG with cross-counter flow.

It was found that the ATS-TEG with $8 \times 2$ TEMs in $\mathrm{x}$ - and z-plane, and with 14 levels of such planes (sub-TEGs) in y-direction gives the highest recovered power from the ATS, see Figure 15. Part of simulation results are shown in Figure 16 and 17. The gross- and net Page 9 of 18 power for different fins height are shown as a function of the exhaust temperature from 100 to $500{ }^{\circ} \mathrm{C}$ and the mass flow up to $2200 \mathrm{~kg} / \mathrm{h}$ which cover the 9-point LHC. Simulations on the coolant system showed that a coolant flow of $20 \mathrm{~L} / \mathrm{min}$ and $40{ }^{\circ} \mathrm{C}$ gives a sufficiently high net power. Therefore, to be able to compare the results from these calculations, the coolant flow and its temperature were kept at these levels.

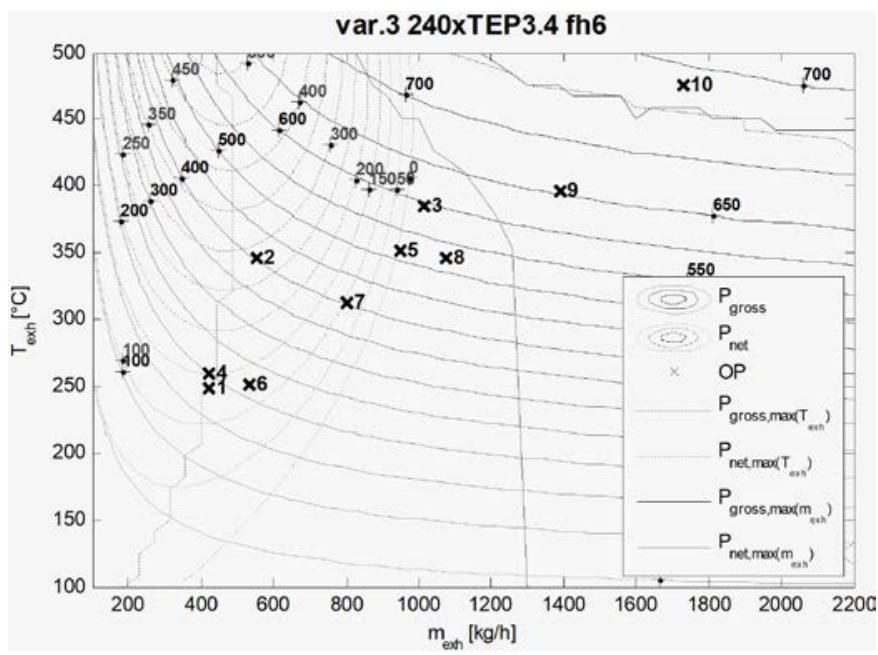

Figure 16. Simulation result showing the gross and net power of ATS-TEG with 240 pc. TEP3.4 modules with fins height of $6 \mathrm{~mm}$. The coolant flow was fixed on $20 \mathrm{~L} / \mathrm{min}$ at $40{ }^{\circ} \mathrm{C}$. Operating points $3,5,8$ and 9 are outside the shell part and do not generate any net power.

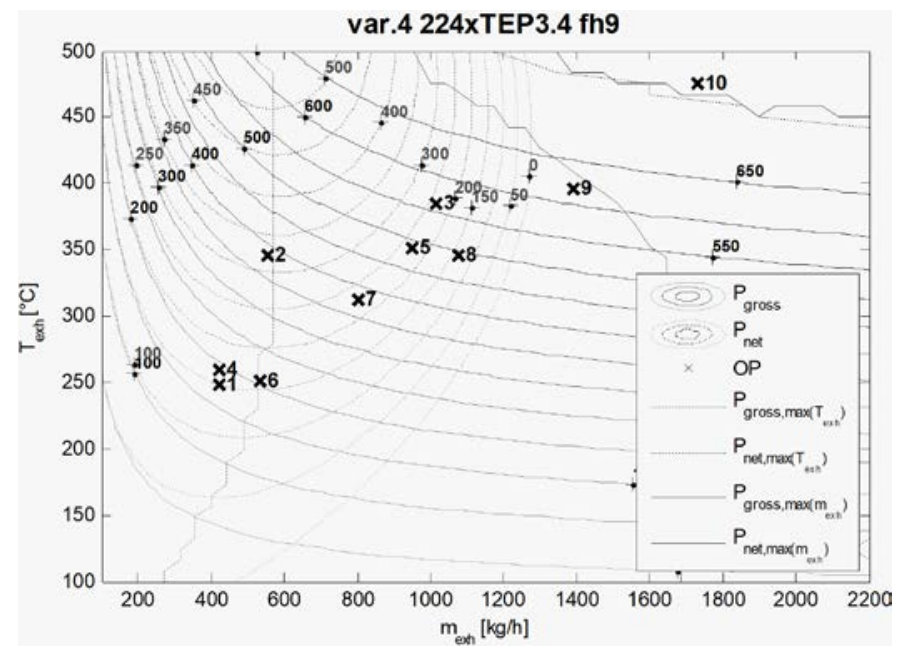

Figure 17. Simulation result showing the gross and net power of ATS-TEG with 224 TEP3.4 modules with fins height of $9 \mathrm{~mm}$. The coolant flow was fixed on $20 \mathrm{~L} / \mathrm{min}$ at $40{ }^{\circ} \mathrm{C}$. Only the operating point 9 is outside the shell part and does not generate any net power.

To make an accurate estimation, the pressure drop in the exhaust and coolant systems were added into the model. The results in Figure 16 and 17 are divided to two parts; the shell part of the graphs shows the net power region and the reciprocal part shows the gross power. As seen in Figure 16, the operating points 3, 5, 8 and 9 are out of the net power region. The highest generated power in this case is approx. $650 \mathrm{~W}$ in point 9 but the net power is zero at that point due to the high amount of losses. If the fins height is changed to $9 \mathrm{~mm}$, the number of modules which can be placed in the defined volume, decrease as well as the generated power. The highest gross power in this case is approx. $620 \mathrm{~W}$. However, the $9 \mathrm{~mm}$-configuration creates a wider range of the net power which covers all operating points 
except point 9 where the losses are still dominating and create a negative net power. Therefore, according to this simulation operating point 9 should partly or completely be bypassed. However, the decision of the amount of bypassing the exhaust gas at this point needs further investigation. The reason of the wider net power region with the new configuration is the lower back pressure in the exhaust system which decreases the losses and thereby generates a higher net power. Furthermore, the larger number of module in the $6 \mathrm{~mm}$ configuration gives higher heat flux through the TEG as well which influences the coolant temperature and affects the vehicle's cooling system. Although, the peak of the generated power is lower with 9 $\mathrm{mm}$ fin height, this is the preferred configuration because of higher average power.

Based on the simulation results in Figure 17 and calculations on the cooling system, a sub-TEG was built to be evaluated. The sub-TEG consists of 16 TEMs on two sides of the HX with offset structure fins, two cooler channels and the force clamps on the top and bottom, see Figure 18. The advantage of a TEG made by sub-TEG structure is that a sub-TEG can easily be replaced if needed. The structure and the cabling of the complete ATS-TEG can be seen in Figure 19. The sub-TEGs were assembled into one single unit and then attached to the ATS system, Figure 20.

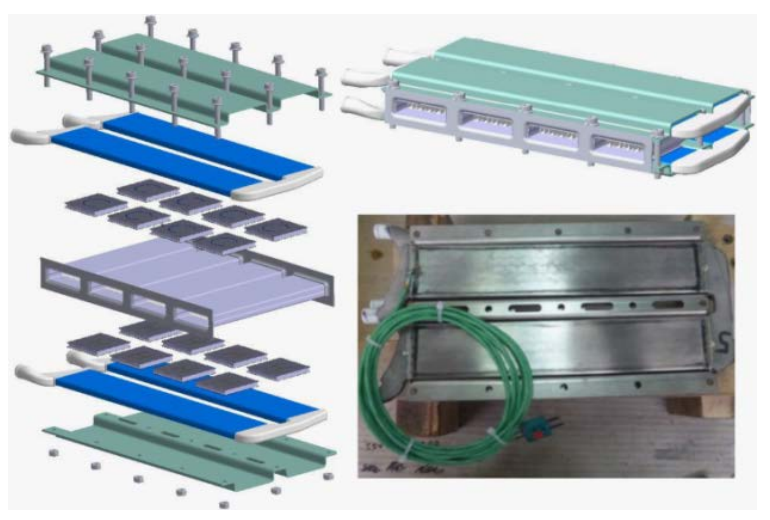

Figure 18. Structure of the sub-TEG in ATS (left) and a complete sub-TEG with 16 modules, 8 on each side of the sub-TEG (right).

In order to evaluate and protect the TEGs in different conditions, a number of sensors were used. In Figure 21, some of the sensors are shown. Besides the sensors shown here, other flow, temperature, and pressure sensors were placed in the cooling system and on particular TEMs. The sensors were also used to develop a control algorithm for the complete system. Both the ATS- and EGR-TEGs went through a functional test and were exposed to the conditions of 9-point LHC. The purpose of the functional test was to detect possible failure as well as comparing the simulations with the measurement results. The result of the ATS-TEG functional test is presented in Figure 22.
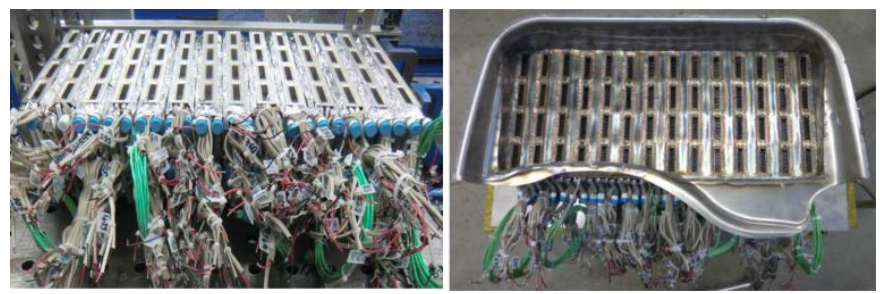

Figure 19. ATS-TEG and the cabling of 224 TEMs. The cables are joints together and will be connected to an electrical power converter.

Due to the available volume and the dissimilar conditions in the EGR and ATS, the TEGs should be adapted and optimized to those Page 10 of 18 conditions which create some natural differences between the ATSand EGR-TEGs. The development and evaluation of different TEGtechniques in this study, was the other reason to the slightly different TEG systems. Some of the main differences can be listed as:

1. The mean gas temperature is approx. $200{ }^{\circ} \mathrm{C}$ higher in the EGR than in the ATS.

2. The mean mass flow is approx. $600 \mathrm{~kg} / \mathrm{h}$ higher in the ATS than in the EGR.

3. The heat exchanger used in the EGR-TEG is the plate rectangular heat exchanger while the offset structure heat exchanger is used in the ATG-TEG.

4. EGR-gases are not actively pumped; the gas flow is due to the pressure drop in the EGR. However, the gas pumps actively through the ATS by the ICE. This is the reason of why the EGR is not able to manage similar amount of pressure drop as the ATS.

5. The design of the EGR-TEG was chosen in a way that the whole TEG was pressed together with a large force, as one single block while the ATS-TEG was made with sub-TEGs and forced together as smaller free units.
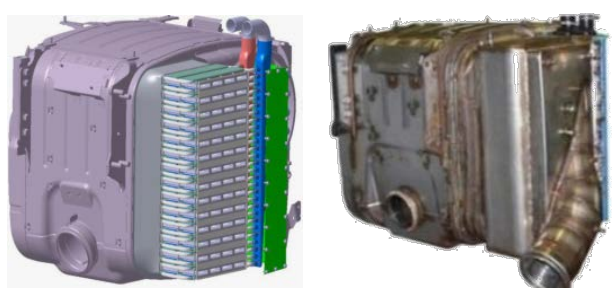

Figure 20. The final version of ATS-TEG where the TEG unit is attached downstream of the ATS.

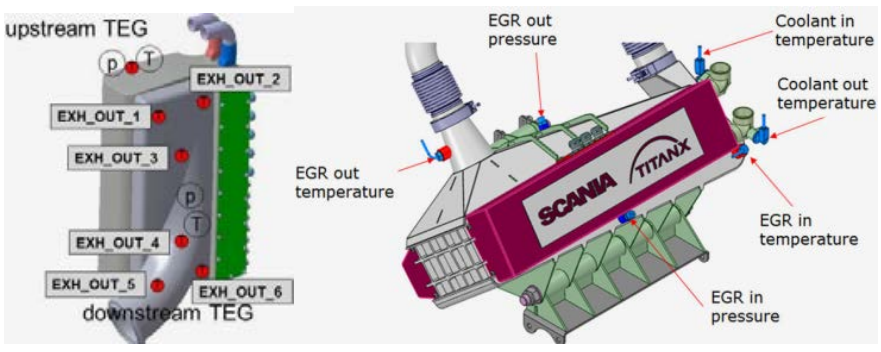

Figure 21. Location of some of the temperature- and pressure sensors in the ATS-TEG (left) and EGR-TEG (right).

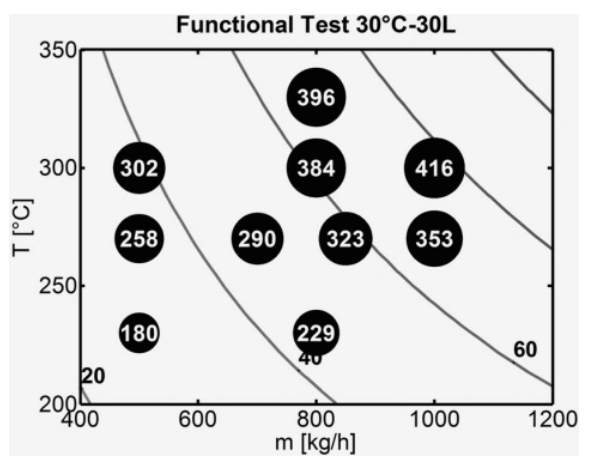

Figure 22. The experimental result of the electrical power output from the ATS-TEG on the test bench at Eberspächer facility, based on 9-point LHC. According to this measurement, the overall efficiency of the ATS-TEG, from heat to electrical power is approximately $2.3 \%$ at $416 \mathrm{~W}$ [41].

\section{Cooling System of the TEGs}

The electrical power increases with increasing the temperature difference between hot and cold side of a TEM. Since the thermal 
conductivity is not zero, the heat reaching the cold side has to be extracted effectively. The total heat power transferred through the TEGs is in the magnitude of $40 \mathrm{~kW}$ according to the calculations. Due to the limited available volume around the ICE, radiation- or convection cooling is not an alternative to pull out the heat in such a system. To design a TEG with highest possible efficiency, the only choice is a liquid cooling system. For a suitable cooling system, two key interfaces should be considered; the interface between the TEM and the HXs on the cold and the hot side as well as the heat transfer from the coolant to the ambient. Based on the available space and the desirable uniform coolant flow, simulations on different configurations on the coolant channels were performed. For instance, it was found that different angles of the coolant entrance to the HX give different distribution and velocity which may create overheating issue of some modules, see Figure 23. Therefore, it is critical to investigate the different configurations to obtain the setup with an even coolant distribution.

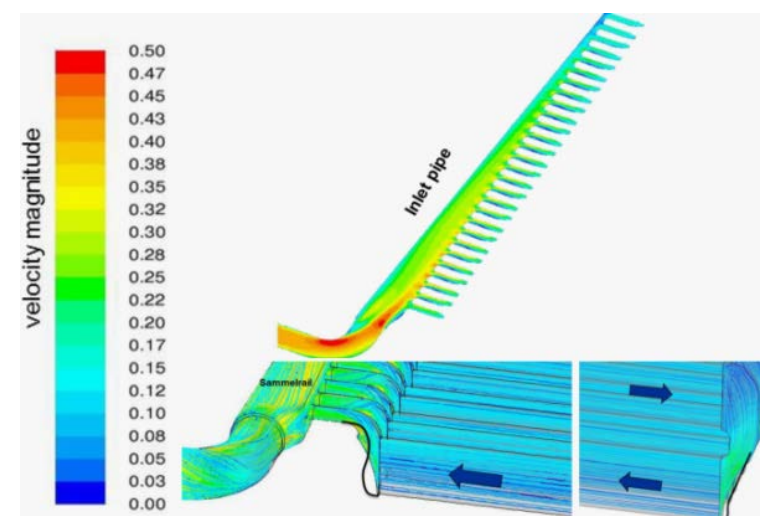

Figure 23. Different configurations of coolant channels were simulated to obtain configuration with the most homogenous coolant flow.

In a heat exchanger, counter flow configuration is the most efficient design. However, this is not always the most practical design dependent on the size of the HX, available volume, and the operation environment. The second best HX-configuration is the cross-counter flow (Figure 15) which is the most suitable one for this kind of applications. Simulations showed desirable results and since this type of HX is less complicated to manufacture, the decision was to employ the cross-counter flow.

The other important heat-interface affecting the design of the TEG's cooling system is the heat transfer from the coolant to the ambient and the cooling circuit outside the TEG. The obvious solution is to use the ordinary cooling circuit and radiator of the vehicle. This solution is the most effortless one since it could easily be integrated to an ordinary stock-vehicle without any extensive modifications. However, there is an optimization problem which based on the heat power and the design of cooling system, needs to be solved. The cooling capacity of the vehicle and possible impairment of the cooling should be considered. In this case the fan power and possibly the inlet temperature to the CAC increases which leads to a less efficient operation and increase the fuel consumption. The other alternative is to employ a separately allocated cooling system for the TEG with the advantage of a lower temperature than the ordinary cooling system. The control of coolant flow can take place individually without affecting the engine temperature with this solution which is preferred from output power point-of-view. Though, designing such a low temperature circuit and radiator (LTR) requires additional space, tubing and an electrical pump which consumes power, a parasitic loss that should be kept as low as possible. On the other hand, there are situations where the capacity of Page 11 of 18 the HTR is not fully used by the ICE and it would be beneficial to utilize the remaining capacity by TEGs keeping the losses low.

In order to investigate the most suitable cooling circuit seven different configurations were studied of which three are presented here. The best configuration in terms of high TEG-power is to have a dedicated LT-circuit and place the radiator in the front of ICE- and the CAC-radiator. However, this set-up will increase the temperatures in the radiators behind and thereby increase the losses in the ICE. Figure 24 shows another configuration with sufficient cooling capability and minimal impact on the ordinary HTR and the CAC, where the TEG-radiator is split into two separate parts. The coolant is first cooled in a radiator (LT1) positioned behind the cold side of the CAC, and then in a further radiator (LT2) positioned in front of the hot side of the CAC. The charge air temperature increases moderately with this configuration, which increases the fuel consumption according to 9-point LHC by about $0.08 \%$. Simulations showed that the coolant obtains a temperature between 25 and $37^{\circ} \mathrm{C}$ at $85 \mathrm{~km} / \mathrm{h}$, with an ambient temperature of $13{ }^{\circ} \mathrm{C}$ without active engine fan in this cooling system. However, this configuration needs additional volume inside engine compartment and increases the complexity of the cooling system.

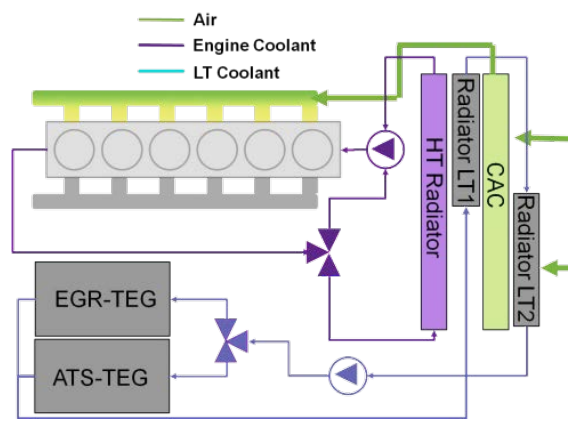

Figure 24. Diagram of the suggested cooling system configuration with two split TEG-radiators (LT1 and LT2) which has minimal influence on the CAC temperature and the ordinary radiator (HT).

Another system which was proposed is a single-radiator configuration where the TEGs cooling system is parallel-connected to the HTR. As seen in Figure 30, the coolant is collected immediately after the HTR and then returning downstream before the engine coolant pump. This configuration uses the cooling capacity of the ordinary cooling system as long as the temperature is fairly low without adding extra losses such as pump power and pressure drop. When the water temperature in the HT-circuit increases so that the TEG power or the ICEs temperature is affected, more cooling capacity from the TEG-LTR can be used. This solution gives the best performance from the total vehicle efficiency point-of-view according to the investigations. Furthermore, since the changes of the truck would have been too extensive employing the other cooling systems, the single-radiator configuration was preferred in this application. It should be noticed that this configuration increases the CAC temperature and the impact of higher CAC temperature needs to be taken into account when making the net power calculations.

\section{Thermal Cycling Test}

In order to measure the performance and possible changes in characteristics of the TEMs, a sub-TEG as shown in Figure 18 was built with 8 TEMs only and thermally cycled on a test. The test bench set-up can be seen in Figure 25. The hot side of the sub-TEG was cycled from $95{ }^{\circ} \mathrm{C}$ to $335{ }^{\circ} \mathrm{C}$. Once the maximum temperature was reached a dwell time of 10 seconds was applied prior to cooling back 
to $95{ }^{\circ} \mathrm{C}$. The complete period of one cycle profile can be seen in Figure 26. While both heating and cooling profiles were dependent on the system set-up and the position of bypass valve, the dwell time was controlled by the system software. The system allowed a cycling time of approx. $400 \mathrm{~s}$ per cycle, which after more than a week of testing, enabled 1605 temperature cycles. To the best of our knowledge, a BiTe-TEG has not previously been thermally cycled with a large number of cycles.

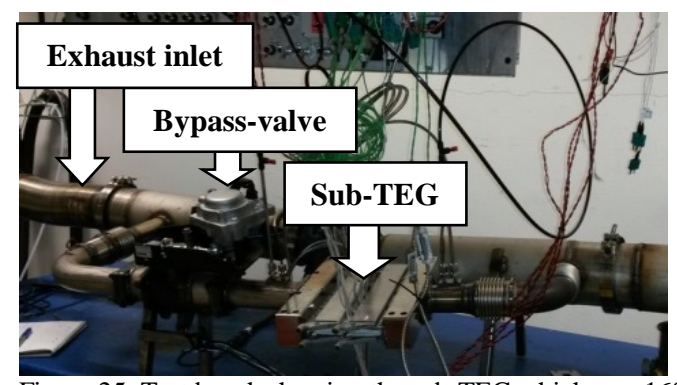

Figure 25. Test bench showing the sub-TEG which was 1605 times thermally cycled during one week. Hot exhaust gas was used as the heat source and water was used as the coolant.

The maximum voltage during the thermal cycling was evaluated for the TEMs. Due to measurement issues, data could be collected for 6 out of 8 modules. The result of this test is presented in Figure 27. The voltage was changed 1-2\% compared to the nominal values for 5 TEMs after the test. The voltage for the TEM at position 10 decreased $7 \%$ compared. This experiment shows that the TEG is still stable and reliable after a long-term thermal cycling. The sub-TEG as well as the individual TEMs were investigated afterwards and no visible damages were found.

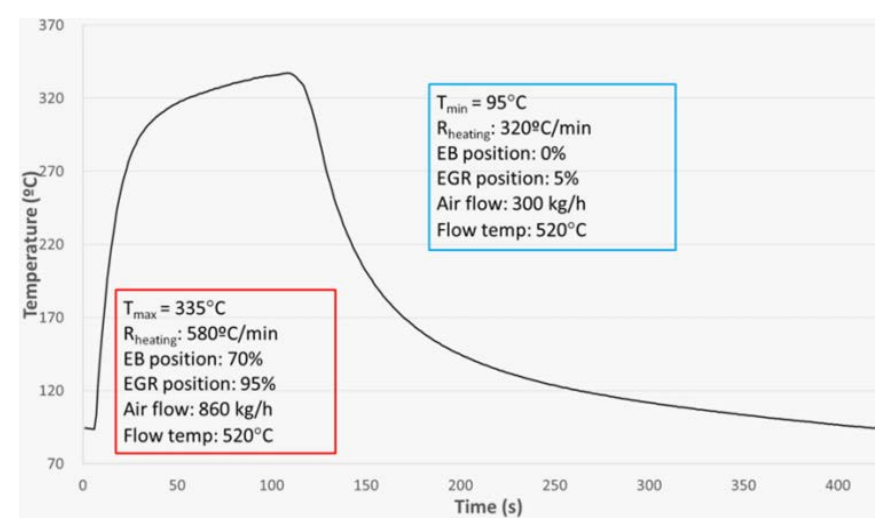

Figure 26. Measured temperature of the hot side as a function of time for one thermal cycle.

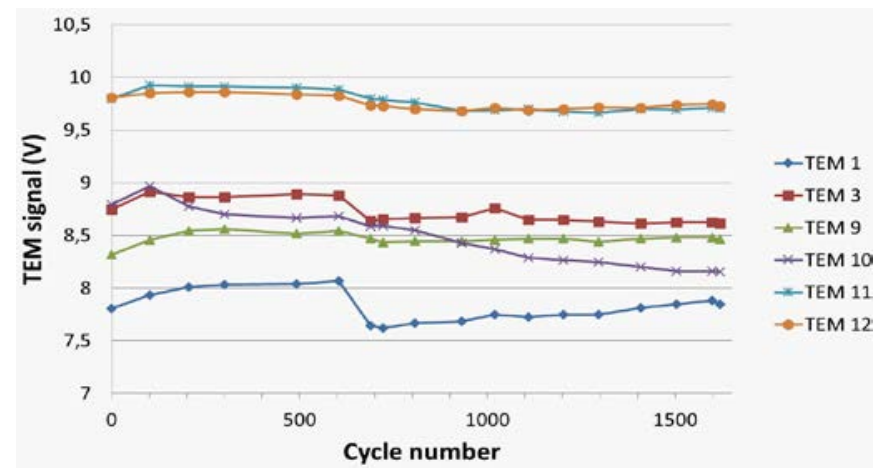

Figure 27. Results of the thermal cycling show the open-load voltage of 6 TEMs in the sub-TEG as a function of number of cycles.

Page 12 of 18

\section{TEG System Actuators}

In order to adapt the TEG to different operating conditions, the system requires four actuators which control and protect the TEG. The most important actuators included in the system are the electric cooling pump to drive the coolant liquid and the electric distribution $3 / 2$ valve, see Figure 28 . The valve was integrated with the cooling system in order to prioritize the coolant flow between the EGR-TEG and the ATS-TEG at different operation conditions. The valve is necessary since the primary EGR-flow, and thereby the EGR temperature, are controlled by the vehicle main ECU based on the driving condition. In some cases the engine may develop high power but with no or small amount of EGR-flow. In such cases there is no need of cooling at the EGR-TEG while required cooling capacity is high in the ATS-TEG.
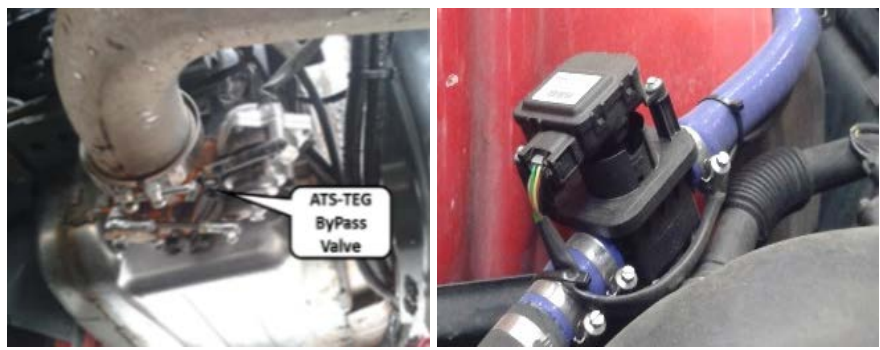

Figure 28. ATS-TEG hot gas bypass valve (left) and the electric distribution valve for the coolant (right).

\section{Parasitic Losses due to on-board TEG}

By adding the TEG to the vehicle several systems of the vehicle may be influenced. Apart from the additional weight and volume, mainly four parasitic effects can be identified. As the cooling system for the TEG has a cooler mounted in front of the main engine and the CAC, these two systems may be affected. Due to an increased pressure drop, also the engine exhaust system is influenced. Additionally, the coolant pump for the TEG consumes power. Each of these effects may reduce the net power generated by the TEG.

\section{Vehicle Cooling Fan Losses}

The engine temperature has a large impact on its performance. Therefore, the TEG should have a minimum influence on the temperatures in the vehicle cooling system. If the temperature increases, the engine management system increases the fan speed. However, in all driving conditions tested it was shown that the temperature of the vehicle cooling system was not affected significantly. Nevertheless, there may be operating conditions e.g. high ambient temperature, when the fan speed must be increased.

\section{CAC Losses}

The losses due to increased temperature in the air inlet system are hard to predict as these depend on for instance the engine architecture and the emission reduction system. However, it is known that an increased air inlet temperature of $10 \mathrm{~K}$ gives $0.5-0.8 \%$ higher fuel consumption in HDVs.

\section{Increased Pressure Drop in Exhaust System}

Increased back pressure resulting from adding a HX or TEG-stack in the tail pipe may have a significant influence of the engine 
performance. The relative fuel consumption increase, $d B S F C$, due to additional pressure drop in the tail pipe is given by

$$
d B S F C[\%]=100 \times \text { ERturbine } \times \frac{d P[\text { bar }]}{I M E P[\text { bar }]},
$$

where ERturbine is the expansion ratio over the turbo charger turbine, $d P$ is the added pressure drop, and IMEP is the indicated mean effective pressure. All variables are dependent on the engine operation point and the engine architecture.

\section{TEG System Coolant Pump}

The vehicle was equipped with an electrically driven coolant pump dedicated for the WHR system. The pump has CAN communication with the electronic control unit of the TEG (TEG-ECU). The power consumed by the pump was measured and sent to the TEG-ECU.

\section{Control System}

Since the TEG is an external system added to a drivable existing test vehicle, it requires a suitable monitor and control system, mainly to control the actuators needed for keeping parasitic losses to an acceptable level and temperatures at nondestructive states. Furthermore, the control system could search the best possible temperature levels over the TEG and compare the gross- and net power to find out the best configurations of valves to maximize the net power. Such a control system, maximum net power tracker (MNPT), needs sensors measuring all type of losses in the system with high accuracy to decide the best possible valve configurations. Simulations on this type of control system were performed and a result of obtained maximum power can be seen in Figure 29. The figure shows the net power as a function of coolant and gas flow. In this case, a maximum net power of $249 \mathrm{~W}$ can be obtained with a coolant flow (CF) of $23 \mathrm{l} / \mathrm{min}$ and exhaust gas of $450 \mathrm{~kg} / \mathrm{h}$. In order to set up the control system, an ECU was used and connected to the vehicle's regular CAN-bus system to retrieve information from the vehicle's sensors and control signals. This unit was used to control the coolant pump, ATS- and EGR gas valves, and could also be used to control the position of distribution valve. Moreover, the ECU logged the sensor data within the TEG for further investigations. Scania has a pending patent application [PCT/SE15051263] on developed MNPT for TEGs in trucks.

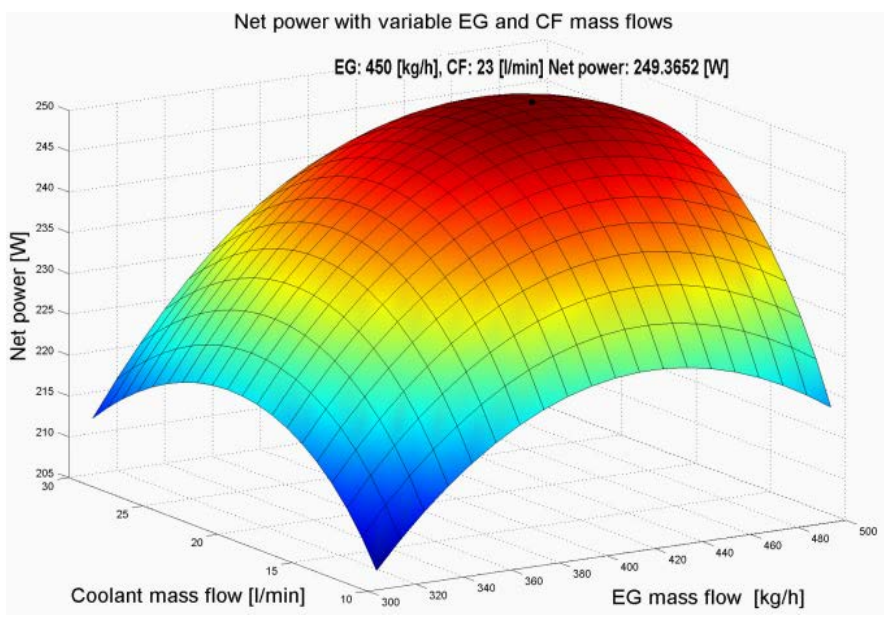

Figure 29. The graph shows the net power generated by an ATS-TEG as a function of the coolant flow (FC) and exhaust gas (EG). Maximum power net power is obtained at $\mathrm{EG}=450 \mathrm{~kg} / \mathrm{h}$ and $\mathrm{CF}=23 \mathrm{l} / \mathrm{min}$.

Page 13 of 18
Since it is impossible to optimize the TEG for all operating points the system was designed to have the optimum output at midlevel of engine load and at 1000-1300 RPM to be efficient for long haulage driving condition. This means that during shorter periods of time the load level and engine speed will be above or under what is optimal for the WHR system, for instance when climbing hills and during accelerations. In these situations, parasitic losses may be at the same level or even above the level of power that the TEGs can recover. In these situations the MNPT should minimize the losses and in extreme cases bypasses the TEG completely. However, the entire functionality of the MNPT could not be evaluated during the measurements presented in this paper due to the limited time.

\section{Control Strategy for the Coolant Flow}

The coolant control system includes the coolant pump and the distribution valve, see Figure 30. The coolant distribution valve is used to reach maximum net power output by lowering the demand for high pump speed through prioritizing the TEG that for the moment needs the most of the coolant flow. However, based on earlier simulation results it was found that a $60 \%-40 \%$ coolant distribution to ATS- and EGR-TEG was sufficient is the most of cases. The main function of the coolant pump was to protect the system against boiling in case of over-temperature on the hot side surface of the TEMs. It could operate completely independent and during the primary tests it operated at 3000 RPM for all LHCs. However, according to the measurements the coolant temperature stayed at $57^{\circ} \mathrm{C}$ at one of the highest possible engine loads. It indicates that the power of the pump could be reduced to decrease the losses, if an active control system is employed.

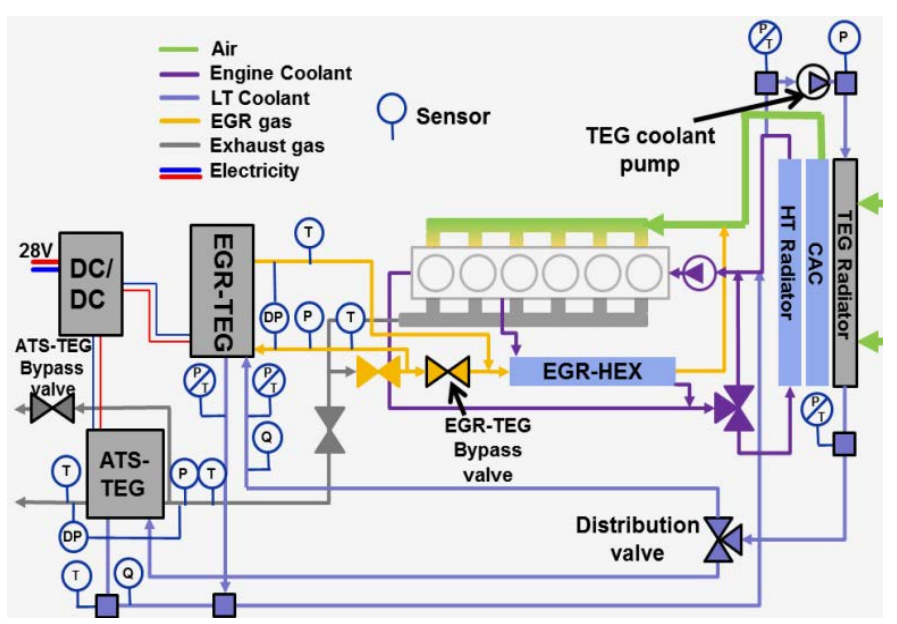

Figure 30. A schematic overview of the complete TEG system on the prototype truck.

\section{Control Strategy for the Bypass Valves}

The valves in the TEG system are employed to bypass the exhaust gases from the TEG and have three main functions; to limit the pressure drop, to protect the hot side of the TEMs from overtemperature, and to protect the cooling system against overload [41]. The HX, placed in the ATS, was designed to pull as much heat as possible out of the exhaust without causing too high back pressure and it was optimized for 30-50\% of maximum mass flow. This was due to the fact that the LHC spends the most of the time at this level of flow. Nevertheless, the increased back pressure, at higher level of engine load, will create power losses which may be higher than the recovered power. This is the reason for implementing the ATS 
bypass valve and controlling it to obtaining the maximum net power. However, during the test it was found that the maximum back pressure was lower than 4 mbar which could be leaved out of the control system to reduce the complexity.

A possible secondary control loop that can be implemented is to protect the TEMs surface from over-temperature in the TEGs. This is needed, because the modules have the limited operation temperature, at maximum $330{ }^{\circ} \mathrm{C}$. The gas temperature after the catalysts can reach up to $500{ }^{\circ} \mathrm{C}$ and in the EGR it can reach the level of $650{ }^{\circ} \mathrm{C}$ which may result in temperature above the limit.

The secondary purpose of the valve is to protect the coolant from boiling. However, no need of this function could be shown during the tests, but high ambient temperature $\left(>35{ }^{\circ} \mathrm{C}\right)$ may need such a function. It is also possible to use the bypass valve to control the coolant temperature which may influence the CAC temperature in the front of the truck. The influence was found to be minor because the bypass valve will be opened anyway by the temperature protection function at the situations that the CAC-temperature is influenced to a major grade.

\section{Over-voltage Protection}

The output of the TEG is connected to the vehicle electrical system through a high efficiency DC/DC converter. The reference value for the output voltage from the DC/DC converter was set as an offset added to the voltage demanded by the vehicle battery management system. If the TEG has the capacity to raise the voltage of the vehicle above the reference voltage, the alternator will reduce its power requirements from the ICE towards zero. If the TEG increases the voltage of the vehicle electrical system above the allowed maximum voltage, the DC/DC converter will reduce the power flow towards the vehicle electrical system until the voltage drops under the maximum voltage. The main purpose of the over-voltage protection is to maintain the normal battery life length and minimize the risk of failures of the vehicle electrical system.

\section{Conditioning of the Electrical Power}

A TEG converts the heat to electrical power which has to be controlled and used in an efficient way when it comes to a drivable vehicle. As seen in Table 2, the temperatures vary between 248 and $396{ }^{\circ} \mathrm{C}$ in the ATS and 318 and $560{ }^{\circ} \mathrm{C}$ in the EGR. Furthermore, the internal resistance of the TEG is relatively high and also changes with the temperature variation. These variations cause two issues resulting in failures and damage in the electrical system, and also make the use of TEGs less beneficial due to the low conversion efficiency. Therefore, employing a DC/DC power converter between the TEG and the electrical system of the vehicle is necessary, see Figure 31. Purposes of the converter are: to handle the power variation from the TEG, generate a constant output voltage, and also to find the optimum operating point to extract the highest available power from the TEG [42].

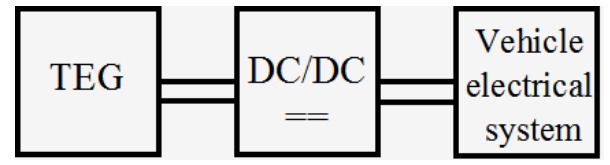

Figure 31. A DC/DC converter is needed to extract the highest available power from the TEG and adapt the voltage level of the TEG to the electrical system of the vehicle.

Page 14 of 18
There are a number of different converter topologies that could be used in a TEG system. However, the automotive industry requests to fulfill some criteria for electronics in vehicles. A converter has to operate safely and be easy to control with a low cost per converted power. In the case of TEG, it should also be able to handle the large variation in power at the same time as it operates with high efficiency for the most of the operating points. There are a few converter topologies which can achieve these criteria. According to the investigations, a step-down converter is the most suitable one for TEGs in automotive applications since the relation between the output and input voltage is linear and high reliability and controllability easily can be obtained in such a converter [43].

The earlier simulation results on the HXs and the output power of the TEG dictated the specifications of the electrical power converter. Since a synchronous converter can be made to operate with high performance, a synchronous step-down was designed and manufactured, see Figure 32. Originally, the power of the TEGs was shared between 8 converter channels but the tests on-board showed that only 4 channels could be used without any additional losses of power which is beneficial in terms of weight and cost. The converters were equipped with current- and voltage sensors and microcontrollers with an optimized Perturb and observe maximum power point tracker (MPPT) algorithm [44]. The task of the MPPT was to extract the highest available power from the TEG. The conveters were mounted on the truck and the data could be sent to the main ECU via the vehicle CAN bus. The measurments on-board showed that the converters kept the efficiency of 97-98\% for the most of operating points.

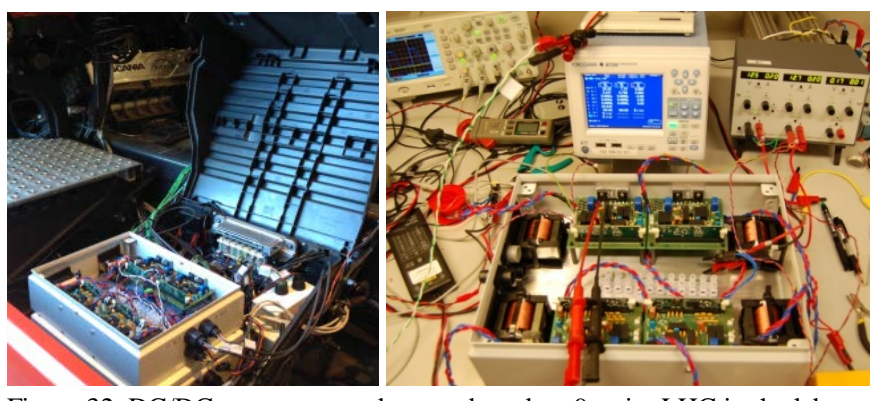

Figure 32. DC/DC converters under tests based on 9-point LHC in the lab (right) and on-board the prototype-truck, connected to the TEGs, the electrical system, and to the CAN-bus of the vehicle (left).

\section{RESULTS}

The results presented in this section are mainly related to the output power of the TEGs while the results of the subparts of the system were shortly presented earlier in each section. When the complete TEG system and its auxiliaries were evaluated in parts, the entire system was integrated to the truck. It was then tested in a dyno-test cell, capable to produce controlled wind speed and ambient temperature, see Figure 33. The experiments were performed during two different occasions. During the first occasion (referred to as CD2) the correct and normal operation was validated and rough measurement results were collected. The second occasion (referred to as CD5) was performed to make more detailed and complete measurements. As seen in Figure 34, the recovered gross power from the ATS-TEG was significantly higher from runs during CD2 than in CD5. The reason is that the cooling fan and the coolant pump were running at higher rate than necessary because of possible risks of damages. This resulted in higher output power as well as higher losses in form of pump power. However, during CD5 the system could be optimized (based on CD2) to have lower losses which 
resulted in lower gross power but higher net power compared to CD2. The total recovered gross power from CD2 was measured to $1 \mathrm{~kW}$.

Different types of measurements were performed to observe the behavior of the system as a whole as well as subsystems. The two main categories were the stationary and transient measurements where the behavior of the system was studied jumping from one point of LHC to another before the complete steady-state condition was reached. A part of the results from a stationary measurement at operating point 1 and a transient measurement can be seen in Figure 35 and 36. As seen in the transient result, the ATS-TEG has a faster response time compared to the EGR-TEG which does not follow the ATS all the time. This is due to the higher gas flow in the ATS and the control system of the EGR which is based on an emission strategy. The time response of the system from change of operating point to change in electrical output power is relatively fast ( $<20 \mathrm{~s})$.
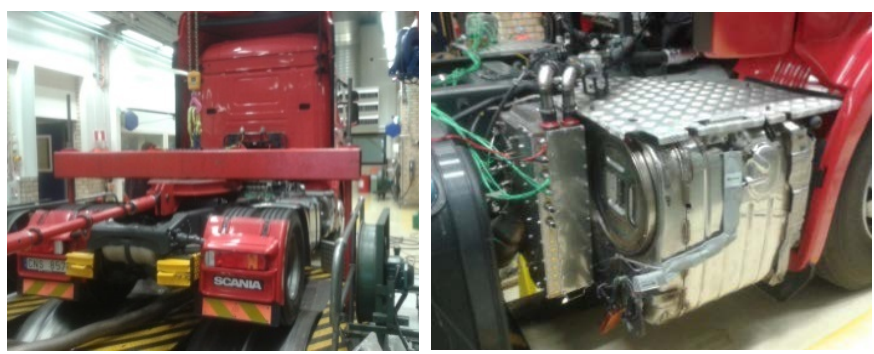

Figure 33. The test-truck equipped with TEGs during CD2 tests in temperature and wind controlled dyno-cell.

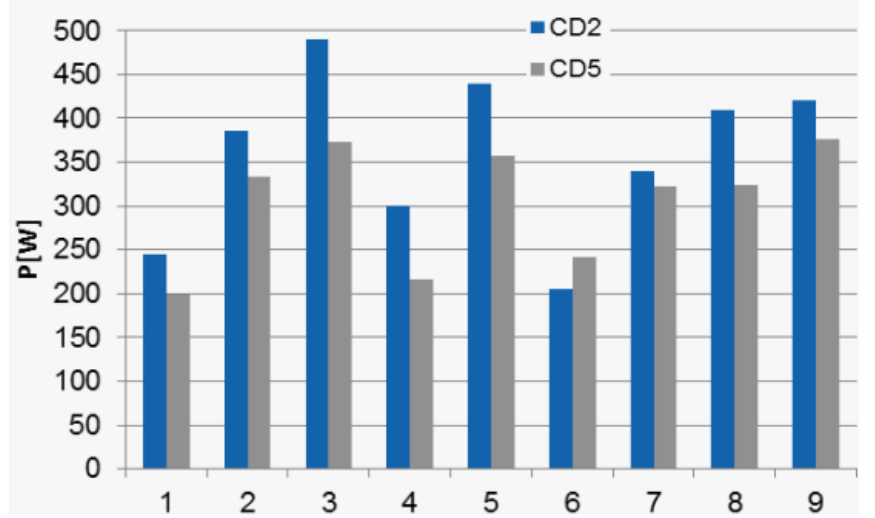

Figure 34. The graph shows the ATS-TEG gross power as a function of LHC driving cycles from two different measurement occasions, CD2 and CD5. The obtained gross power was higher for both TEGs during CD2.

Detailed studies on the obtained results were performed to be able to accurately update the models for the system. Using the new models, simulations were run from which it was found that the primary simulation results had approximately $20 \%$ deviation while the updated results had approximately $1 \%$ deviation from the measurement results. The new models give the opportunity to predict the behavior of the TEG using other types of TEM and optimize the system to obtain higher performance. The simulation and measurement results as well as simulation results with other material than BiTe are collected in Table 6. It was found that TEMs with Quantum Well (QW) thermocouple are able to generate the highest gross and net powers in such a system.

As seen in the result, a mean gross power over time of approx. $450 \mathrm{~W}$ and a mean net power of $225 \mathrm{~W}$ were obtained from the TEGs. As expected, operating point 9 will not generate any net power because of the high amount of backpressure and the increased CAC Page 15 of 18 temperature. Therefore, this point has to be bypassed to minimize the losses.

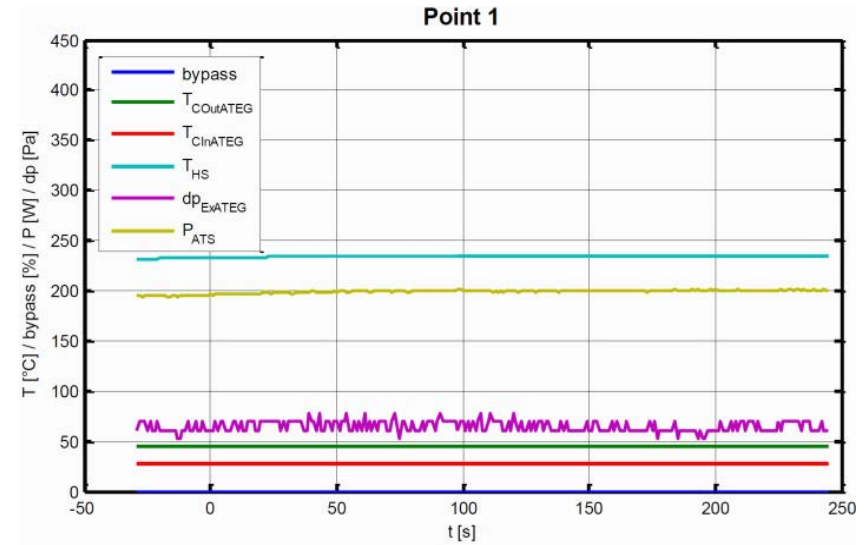

Figure 35. Steady-state measurement in point 1 of LHC, showing the electrical power of the ATS-TEG, the temperature of the LT-circuit into and out of the TEG, the hot-side temperature of the modules, the pressure drop of the exhaust gases and the position of the bypass valve.

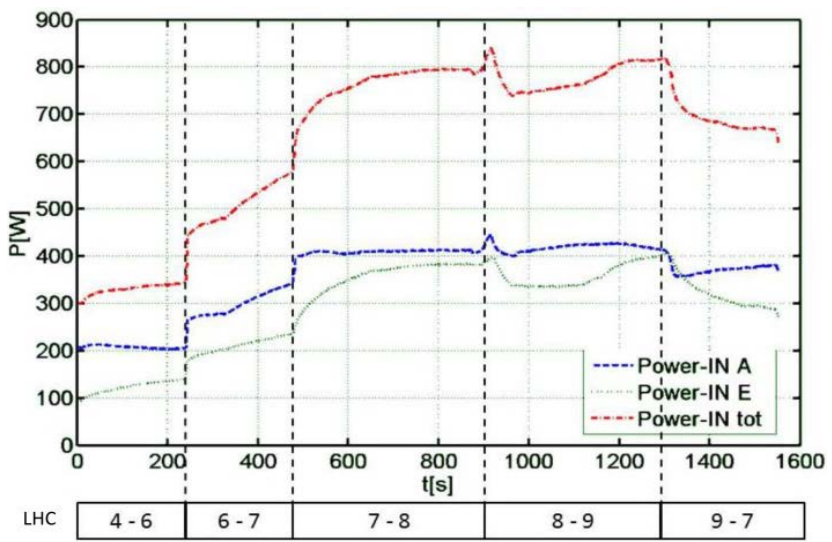

Figure 36. The graph shows the results of a transient measurement of the TEGs electrical power as a function of driving cycles and time. The jumps between the driving cycles are marked on the time axis. "Power-IN A" denotes the TEG power from the ATS and "Power-IN E" denotes the TEG power from the EGR.

Table 6. The final result of the steady state measurement from CD5 and prediction of the recovered power for some other materials. The table shows the gross- vs. net power form measurement and simulations.

\begin{tabular}{|c|c|c|c|c|c|c|c|c|c|c|c|}
\hline $\begin{array}{l}\text { TEG Power } \\
{[\mathrm{W}]}\end{array}$ & $\begin{array}{l}\text { Wriving } \\
\text { cycle } \\
\text { Material }\end{array}$ & 1 & 2 & 3 & 4 & 5 & 6 & 7 & 8 & 9 & $\begin{array}{c}\text { Weighted } \\
\text { Average } \\
\text { power LH }\end{array}$ \\
\hline & BiTe & 199 & 326 & 362 & 215 & 350 & 246 & 300 & 327 & 368 & \\
\hline $\begin{array}{c}\text { ATS-TEG } \\
\text { Sim. Gross }\end{array}$ & BiTe & 185 & 340 & 377 & 229 & 362 & 260 & 350 & 317 & 375 & 277 \\
\hline $\begin{array}{c}\text { EGR-TEG } \\
\text { Meas. Gross }\end{array}$ & BiTe & 46 & 217 & 247 & 83 & 290 & 123 & 330 & 364 & 408 & \\
\hline $\begin{array}{l}\text { EGR-TEG } \\
\text { Sim. Gross }\end{array}$ & BiTe & 50 & 205 & 238 & 90 & 285 & 125 & 288 & 365 & 410 & 171 \\
\hline $\begin{array}{l}\text { Total Gross } \\
\text { Measured }\end{array}$ & BiTe & 245 & 543 & 609 & 298 & 640 & 369 & 630 & 691 & 776 & \\
\hline $\begin{array}{l}\text { Total Gross } \\
\text { Simulated }\end{array}$ & BiTe & 235 & 545 & 615 & 319 & 647 & 385 & 638 & 682 & 785 & 448 \\
\hline $\begin{array}{l}\text { Total Net } \\
\text { Simulated }\end{array}$ & BiTe & 131 & 369 & 37 & 204 & 222 & 254 & 328 & 65 & -170 & 225 \\
\hline $\begin{array}{c}\text { Total Gross } \\
\text { Simulated } \\
\end{array}$ & TAGS & 315 & 895 & 1020 & 385 & 979 & 470 & 875 & 1015 & 1148 & 596 \\
\hline $\begin{array}{l}\text { Total Net } \\
\text { Simulated }\end{array}$ & TAGS & 216 & 719 & 441 & 269 & 553 & 336 & 565 & 393 & 185 & 371 \\
\hline $\begin{array}{c}\text { Total Gross } \\
\text { Simulated }\end{array}$ & QW & 1140 & 2700 & 2885 & 1305 & 2850 & 1580 & 2630 & 2890 & 3135 & 1878 \\
\hline $\begin{array}{l}\text { Total Net } \\
\text { Simulated }\end{array}$ & QW & 1031 & 2529 & 2306 & 1187 & 2428 & 1446 & 2318 & 2268 & 2200 & 1653 \\
\hline
\end{tabular}




\section{CONCLUSION}

In this paper the general procedures of designing, manufacturing, and testing a complete WHR system based on thermoelectric generation on a Scania class 8 truck (440 HP Scania 4x2 long haulage truck, Euro 6 Incentive) was described. The engine was equipped with both EGR and ATS with Diesel Particulate Filter (DPF) and Selective Catalytic Reduction (SCR) technology. The WHR consists of two Thermoelectric Generators with individual HXs, TEMs, shared cooling system and controllable coolant flow distribution valves, and power converters. The TEGs were designed based on 9 different engine loads. Weighted together they form an artificial LHC. Furthermore, the TEGs had individual gas-bypass to control the amount of gas passing through and the hot side temperature. The TEGs were placed upstream the EGR and downstream the ATS in the truck. In order to control the TEG actuators and to log the data, the TEG-system was connected to a dedicated ECU which in turn was a part of the control system of the truck. This fact makes the truck as a normal drivable vehicle which can be used on roads while recovering power from the waste heat in the exhaust system which is unique in this field. Furthermore, during the design process and measurements, the pressure losses of the gas- and the coolant streams were considered and the results presented show the gross, net and average recovered power.

From the measurements based on the 9-point LHC the recovered power reached $1 \mathrm{~kW}$ during CD2 tests. However, the losses are usually a significant factor dictating the amount of the actual net power. One of the most significant losses is the power consumption of the coolant pump which could reach $250 \mathrm{~W}$. It should be kept in mind that the system was not tuned as a unit and the MNPT was not calibrated and completely implemented. It is estimated that a detailed calibration together with MNPT could give $50 \%$ higher net power than the current result. In order to evaluate the system and estimate the amount of the fuel and emission reduction accurately, the mean value of the net power has to be considered. In many studies the losses in such a system are underestimated or completely ignored. It was shown that in operating points where the ICE develops a high amount of power, losses such as backpressures, pump power, and the raise of CAC temperature dominate the recovered TEG power. While the ICE develops high power and thereby gross TEG power is high, the net TEG power may be zero or negative meaning increased fuel consumption. However, this issue can be solved by a tuned MNPT bypassing the gas through TEGs.

Due to the different environments in the ATS and EGR, the TEGs had to be designed for each environment. The most important parameter considered during the design phase was the added backpressure which resulted in different design of HX. Another important difference between the EGR- and ATS-TEG was the body of the TEGs. The EGR-TEG was designed to be pressed in total as a single unit while the ATS-TEG was built up with sub-TEGs. There are benefits and drawbacks of both methods. A single unit is much easier to build and handle but it is challenging to ensure an even pressure over every single module during assembly. On the other hand, a TEG built by sub-units is more complicated to handle but a more even pressure can be obtained. Furthermore, replacing a subTEG can easily be done at failure.

Thermoelectric generators may become an interesting technology for exhaust gas heat recovery because the tested system showed a stable behavior, and so far without any failures during the tests performed in dyno-cell and on road. It was found that the TEG is an effortless system with high controllability and less complexity compared to Page 16 of 18 other types of WHR for automotive applications. The most important reason is that the time constant of a TEG is relatively low and therefore it responds quickly to changes in heat from the ICE. At the same time, this time constant is slow compared to the electronics controlling the valves and power converters which makes the entire system stable and extremely simple to control. Furthermore, this study shows that a complete TEG can be integrated to an existing HDV. Obviously, the implementation would be straightforward if the vehicle would be prepared for TEG in series production.

It should be mentioned that to develop a beneficial and economical TEG system for vehicle applications, it is not sufficient to only optimize the heat exchanger or the module itself. It is necessary to optimize the complete vehicle system as a unit, and especially the module selection has to be considered. Today's modules are designed for high power density, which often means that the modules require a high heat flux supply to maintain a good efficiency. However, in automotive exhaust gas systems, the available heat flux is limited by different parameters such as the cooling system and pressure drop, which influence the engine efficiency. In other words, it is not enough to reach high module efficiency on a test bench that supplies virtually unlimited heat flux. Using modules that generate high power means a high flux through the module resulting in higher coolant temperature which requires larger cooling capacity. Since, the heat source and cooling capacity are limited in a vehicle, modules with relatively low heat flux are preferred.

Another issue related to the TEMs is the operating temperature which is limited to a small working range with a high efficiency. However, in automotive applications, a wide temperature range with high efficiency at lower nominal temperature is required. For a useful integration, the modules need to withstand the temperature peaks, but it should not be the design point for highest efficiency.

The efficiency of the modules (BiTe) commercially available today (2016) is still far from automotive industry requirements, why a groundbreaking thermoelectric material is necessary. In order to have an economic beneficial integration into automotive applications, the power output per installation space/weight of future TEGs has to increase, and the price per generated power needs to decrease. The estimated cost of the TEGs per mean net power is approx. 150 \$/W and the power per weight is $1.125 \mathrm{~W} / \mathrm{kg}$ in this study. Clearly, the cost will decrease in a series production and the generated net power will increase if the system is perfectly tuned. However, according to this study, materials with higher $Z T$ will have a significant impact on the generated power. The simulation results in Table 6 indicate an almost 10 times improvement in power if QW material is used in such an application. This will save approximately $4500 \mathrm{~L}$ diesel in a HDV.

\section{REFERENCES}

[1] J. Olivier, G. Janssens-Maenhout, M. Muntean and P. Peters, "Trends in Global CO2 Emissions," PBL Netherlands Environmental Assessment Agency, Netherland, 2014.

[2] "The 2020 climate and energy package," 1407 2015. [Online]. Available: http://ec.europa.eu/clima/policies/strategies/2020. [Accessed 1507 2015].

[3] "ACEA," [Online]. Available: http://acea.be/industrytopics/tag/category/environment-and-sustainability. [Accessed 1507 2015].

[4] "Reducing emissions from transport," [Online]. Available: http://ec.europa.eu/clima/policies/transport. [Accessed 0107 2014]. 
[5] W. Ping, J. Chunjun, T. Bin and S. Xigeng, "Effect of Common Rail System on Vehicle Engine Combustion Performance," in Optoelectronics and Image Processing (ICOIP), 2010 International Conference on, Haiko, 2010.

[6] H. Kang, C. Hanbao, Q. Jianwen and A. Shijie, "The exploration of HCCI combustion in the high-power direct-injection diesel engine," in Computing, Control and Industrial Engineering (CCIE), 2011 IEEE 2nd International Conference on, Wuhan, 2011.

[7] I. Arsie, A. Cricchio, C. Pianese, M. D. Cesare and W. Nesci, "A Comprehensive Powertrain Model to Evaluate the Benefits of Electric Turbo Compound (ETC) in Reducing CO2 Emissions from Small Diesel Passenger Cars," in SAE Technical Paper, 2014.

[8] M. Hatami, D. D. Ganji and M. Gorji-Bandpy, "A review of different heat exchangers designs for increasing the diesel exhaust waste heat recovery," Renewable and Sustainable Energy Reviews, vol. 37, pp. 168-181, 2014.

[9] D. Hountalas, C. Katsanos and V. Lamaris, "Recovering Energy from the Diesel Engine Exhaust Using Mechanical and Electrical Turbocompounding," in SAE Technical Paper, 2007.

[10] J. Thomas, "Drive Cycle Powertrain Efficiencies and Trends Derived from EPA Vehicle Dynamometer Results," SAE Int. J. Passeng. Cars - Mech. Syst., vol. 7, pp. 1374-1384, 2014.

[11] F. Liming, G. Wenzhi, Q. Hao and X. Bixian, "Heat Recovery from Internal Combustion Engine with Rankine Cycle," in Power and Energy Engineering Conference (APPEEC), 2010 Asia-Pacific, Chengdu, 2010.

[12] M. Wei, J. Fang, C. Ma and S. N. Danish, "Waste heat recovery from heavy-duty diesel engine exhaust gases by medium temperature ORC system," Science China Technological Sciences, vol. 54, no. 10, pp. 2746-2753, 2011.

[13] S. Amicabile, J.-I. Lee and D. Kum, "A comprehensive design methodology of organic Rankine cycles for the waste heat recovery of automotive heavy-duty diesel engines," Applied Thermal Engineering, vol. 87, pp. 574-585, 2015.

[14] J. G. Haidar and J. Ghojel, "Waste heat recovery from the exhaust of low-power diesel engine using thermoelectric generators," in Thermoelectrics, Proceedings ICT, International Conference on, Beijing , 2001.

[15] A. R. Kahn, J. D. Hixson, J. E. Puffer and E. Bakken, "ThreeYears' Clinical Experience with Radioisotope Powered Cardiac Pacemakers," Biomedical Engineering, IEEE Transactions on, Vols. BME-20, no. 5, pp. 326-331, 1973.

[16] P. Dyches, "Radioisotope Power Systems," NASA, [Online]. Available: http://solarsystem.nasa.gov/rps. [Accessed 0608 2015].

[17] L. A. Fisk, "Journey into the Unknown Beyond," Science, vol. 309, pp. 2016-2017, 2005.

[18] M. Srinivasan and S. Praslad, "Advanced Thermoelectric Energy Recovery System in Light Duty and Heavy Duty Vehicles: Analysis on Technical and Marketing Challenges," in Power Electronics and Drives Systems, PEDS. International Conference on, Kuala Lumpur, 2005.

[19] J. Bass, N. Elsner and F. Leavitt, "Performance of the $1 \mathrm{~kW}$ thermoelectric generator for diesel engines," in the International Conference on Thermoelectrics, Kansas City, Missouri, 1994.

[20] J. Bass, A. Kushch and N. Elsner, "Thermoelectric Generator (TEG) for Heavy Diesel Trucks," in International Conference on Thermoelectrics: Proceedings ICT2001, Beijing, 2001.
[21] S. KUMAR, S. D. HEISTER, X. XU, J. R. SALVADOR and G. P. MEISNER, "Thermoelectric Generators for Automotive Waste Heat Recovery Systems Part II: Parametric Evaluation," Journal of Electronic Materials, vol. 42, no. 6, pp. 944-955, 2013.

[22] K. Matsubara, "Development of a high efficient thermoelectric stack for a waste exhaust heat recovery of vehicles," in Thermoelectrics, Proceedings ICT, Twenty-First International Conference on, 2002.

[23] Q. E. Hussain, D. R. Brigham and C. W. Maranville, "Thermoelectric Exhaust Heat Recovery for Hybrid Vehicles," SAE International Journal of Engines, vol. 2, pp. 1132-1142, 2009.

[24] I. Arsie, A. Cricchio, V. Marano, C. Pianese, M. D. Cesare and W. Nesci, "Modeling Analysis of Waste Heat Recovery via Thermo Electric Generators for Fuel Economy Improvement and CO2 Reduction in Small Diesel Engines," SAE International Journal of Passenger Cars - Electronic and Electrical Systms, vol. 7, pp. 246-255, 2014.

[25] Y. DENG, T. HU, C. SU and X. YUAN, "Fuel Economy Improvement by Utilizing Thermoelectric Generator in HeavyDuty Vehicle," Journal of Electronic Materials, pp. 1-8, 2016.

[26] D. Rowe, Handbook of THERMOELECTRICS, CRC Press LLC, 1995.

[27] J. Sootsman, D. Chung and Mercouri Kanatzidis, "New and Old Concepts in Thermoelectric Materials," Angewandte Chemie International Edition, vol. 48, no. 46, pp. 8616-39, 2009.

[28] G. J. Snyder and E. S. Toberer, "Complex thermoelectric materials," Nature Materials, vol. 7, no. 2, pp. 105-114, 2008.

[29] D. M. Rowe, Thermoelectrics Handbook-MACRO TO NANO, CRC Press Inc, 2006.

[30] F. Rosi, "Thermoelectricity and thermoelectric power generation," Solid-State Electronics, vol. 11, no. 9, pp. 849-848, 1968.

[31] F. Rosi, E. Hockings and N. Lindenblad, "SEMICONDUCTING MATERIALS FOR THERMOELECTRIC POWER GENERATION," Radio Corporation of America, vol. 22, 1961.

[32] A. D. LaLonde, Y. Pei and G. J. Snyder, "Reevaluation of PbTe1-xIx as high performance n-type thermoelectric material," Energy \& Environmental Science, vol. 4, no. 6, pp. 2090-96, 2011.

[33] G. Joshi, X. Yan, H. Wang, W. Liu, G. Chen and Z. Ren, "Enhancement in Thermoelectric Figure-Of-Merit of an N-Type Half-Heusler Compound by the Nanocomposite Approach," Advanced Energy Materials, vol. 1, no. 4, pp. 643-647, 2011.

[34] J. P. Heremans, V. Jovovic, E. S. Toberer, A. Saramat, K. Kurosaki, A. Charoenphakdee, S. Yamanaka and G. J. Snyder3, "Enhancement of thermoelectric efficiency in PbTe by distortion of the electronic density of states," Science, vol. 321, pp. 554557, 2008.

[35] B. Yu, M. Zebarjadi, H. Wang, K. Lukas, H. Wang, D. Wang, C. Opeil, M. Dresselhaus, G. Chen and Z. Ren, "Enhancement of Thermoelectric Properties by Modulation-Doping in Silicon Germanium Alloy Nanocomposites," Nano Lett, vol. 12, no. 4, pp. 2077-82, 2012.

[36] A. Saramat, G. Svensson, A. E. C. Palmqvist, C. Stiewe, E. Mueller, D. Platzek, S. G. K. Williams, D. M. Rowe, J. D. Bryan and G. D. Stucky, "Large thermoelectric figure of merit at high temperature in Czochralski-grown clathrate," Appl. Phys, vol. 99, p. 23708, 2006. 
[37] J. Horák, K. Čermák and L. Koudelka, "Energy formation of antisite defects in doped Sb2Te3 and Bi2Te3 crystals," Journal of Physics and Chemistry of Solids, vol. 47, no. 8, pp. 805-809, 1986.

[38] S. N. CHIZHEVSKAYA och L. E. SHELIMOVA,

"Electroactive and electroinactive dopants in Bi2Te3 and their interaction with antisite defects," Inorganic materials, vol. 31, nr 9, pp. 1083-95, 1995.

[39] K. Borkowski and J. Przyłuski, "Investigation of vacuum deposition of Bi2Te3 - based thermoelectric materials," Materials Research Bulletin, vol. 22, no. 3, pp. 381-387, 1987.

[40] D.-Y. Chung, T. P. Hogan, M. Rocci-Lane, P. Brazis, J. R. Ireland, C. R. Kannewurf, M. Bastea, C. Uher and M. G. Kanatzidis, "A New Thermoelectric Material: CsBi4Te6," Am. Chem. Soc, vol. 126, no. 20, pp. 6414-28, 2004.

[41] F. Frobenius, G. Gaiser, U. Rusche and B. Weller, "Thermoelectric Generators for the Integration into Automotive Exhaust Systems for Passenger Cars and Commercial Vehicles," Journal of Electronic Materials, no. 0361-5235, pp. 1-8, 2015.

[42] A. Risseh and H. P. Nee, "Design of high-efficient converter for on-board Thermoelectric Generator," in Transportation Electrification Asia-Pacific, IEEE Conference and Expo, Beijing, 2014.

[43] A. Risseh and H. P. Nee, "High-efficiency step-down converter for on-board thermoelectric generators on heavy duty vehicles," in Power Electronics and ECCE,9th International Conference on, Seoul, 2015.

[44] N. Femia, G. Petrone, G. Spagnuolo and M. Vitelli, "Optimization of Perturb and Observe Maximum Power Point Tracking Method," IEEE TRANSACTIONS ON POWER ELECTRONICS, vol. 20, no. 4, pp. 963 - 973, 2005.

[45] J. R. Thome, "Heat Transfer to Air-Cooled Heat Exchangers," in HEAT TRANSFER ENGINEERING DATA BOOK III, Wolverine Tube, Inc, pp. 1-4.

\section{Contact Information}

risseh@kth.se OR arashrisseh@gmail.com, hansi@kth.se , jan.dellrud@scania.com

$\begin{array}{ll}\text { Abbreviations } \\ \text { TEM } & \text { Thermoelectric module } \\ \text { TEG } & \text { Thermoelectric generator } \\ \text { HX } & \text { Heat exchanger } \\ \text { HDV } & \text { Heavy duty vehicle } \\ \text { EGR } & \text { Exhaust gas recycling } \\ \text { ATS } & \text { After treatment system } \\ \text { MPPT } & \text { Maximum power point tracker } \\ \text { MNPT } & \text { Maximum net power tracker } \\ \text { CAC } & \text { Charge air cooler } \\ \text { WHR } & \text { Waste heat recovery } \\ \text { LHC } & \text { Long haulage cycle } \\ \text { CAN } & \text { Control area network } \\ \text { SCR } & \text { Selective catalytic reduction } \\ \text { ORC } & \text { Organic rankine cycle } \\ \text { ICE } & \text { Internal combustion engines } \\ \text { QW } & \text { Quantum well } \\ \text { ECU } & \text { Electronic control unit } \\ \text { DPF } & \text { Diesel particulate filter } \\ \text { LTR } & \text { Low temperature radiator } \\ \text { HTR } & \text { High temperature radiator } \\ \text { EPA } & \text { Environmental protection agency } \\ \text { Page 18 of 18 }\end{array}$

